\title{
A review of in vivo and in vitro aspects of alcohol-induced dose dumping
}

Susan D'Souza ${ }^{1 *}$, Stephen Mayock ${ }^{2}$ and Alger Salt ${ }^{3}$

\begin{abstract}
This review provides a comprehensive list of in vivo and in vitro studies that have investigated alcohol induced dose dumping (AIDD) in modified release dosage forms. Of the numerous classes of drugs commercially available as modified release products, opioids, centrally acting drugs, and drugs with a narrow therapeutic index present high risks from dose dumping, despite being formulated in a manner that releases drug in a tailored or delayed fashion. Awareness of AIDD has led to the withdrawal of a few marketed products by Regulatory Agencies, and black box warnings on others. Since then, significant effort has focused on proving the robustness of a formulation when co-ingested with alcohol. Patient risk is deemed to be low if the formulation and its performance is unimpaired by the presence of $0-40 \%$ alcohol under in vivo and in vitro conditions.
\end{abstract}

Keywords: Alcohol induced dose dumping (AIDD), In vitro, In vivo, Regulatory, Opioids, Centrally acting drugs, Narrow therapeutic index

\section{Background}

In comparison to an immediate release (IR) dosage form, administration of a drug as an oral controlled release (CR), modified release (MR) or extended release (ER) product is a popular approach to ensuring convenience of dosing and sustained therapeutic blood levels over a prolonged time interval $(12-24 \mathrm{~h})$. Thus, errors in dosing compliance by the patient or breakthrough pain in the case of pain medications commonly observed with multiple daily dosing (i.e. every 4-6 h) of an IR dosage form, can be easily mitigated by ingestion of a single tablet or capsule formulated as a CR, MR or ER product (henceforth abbreviated as ' $M R$ dosage forms') (Smith et al. 2010). These advantages have led to a large number of drugs being formulated and marketed as MR dosage forms. In contrast to an IR tablet or capsule, MR dosage forms contain larger amounts of active pharmaceutical ingredient and different excipients that allow the drug to be released in a slow modulated fashion.

A major risk of a MR dosage form is its potential to release the drug rapidly. As an example, several studies note that MR preparations of theophylline show higher

\footnotetext{
* Correspondence: dsouzas@mail.com

${ }^{1}$ Tesaro Inc., 1000 Winter Street, Suite \#3300, Waltham, MA 02451, USA Full list of author information is available at the end of the article
}

serum levels in the fed state (food induced change) (Hendeles et al. 1985; Hendeles et al. 1984; Steffensen \& Pedersen 1986; Karim et al. 1985a, b). Such rapid drug release from a MR dosage form, i.e. dose dumping, results in the administration of a single bolus dose leading to increased exposure levels, possible safety issues and adverse events. This situation is of most concern with drugs that have a narrow therapeutic index or centrally acting drugs, and will impact clinical efficacy. As a result, CDER (Center for Drug Evaluation and Research) published a guidance document on the design of clinical studies to assess the effects of food on the rate and extent of absorption of a drug under fed and fasted conditions (CDER/FDA 2002).

For this reason, MR dosage forms are designed in a manner such that drug release is well controlled. One way to accomplished this is by entrapping the drug in a matrix that contains a suitable hydrophobic and/or a hydrophilic polymer that regulates drug release and prevents dose dumping. Potential food-induced changes to release rates are determined at the clinical stage by conducting in vivo food effect studies. More commonly, MR dosage forms undergo analytical testing to ensure batchto-batch uniformity of content as well as meet defined in vitro dissolution specifications that provide assurance of the drug being released in its' intended fashion. Thus 
we note that changes in release rates of MR dosage forms have also been observed with food, but the focus of this paper is with alcohol.

Over the years, several types of drugs have been formulated as MR dosage forms, including drugs with a narrow therapeutic index like theophylline used in the treatment of respiratory disorders (Walden et al. 2007). Additionally opioids (e.g. morphine, hydromorphone, oxycodone, dihydrocodeine, and tramadol) used to treat moderate to severe pain associated with cancer are frequently formulated into MR dosage forms (Barkin et al. 2009). These drugs have a short half-life in vivo, thus making them excellent candidates for delivery via MR dosage forms where therapy is required for more than a few days. Depending on the type of the drug incorporated into a MR dosage form and the type of excipients or technology used, drug release can be tailored to modify in vivo absorption, as well as pharmacokinetic and pharmacodynamic properties.

Despite being designed to modulate drug release, dose dumping from MR dosage forms containing opioid drugs has become an area of particular concern for regulators. In 2005, Palladone $\mathrm{XL}^{\mathrm{zm}}$ (hydromorphone hydrochloride), was withdrawn from the market due to a clinical finding that concomitant ingestion of ethanol (alcohol) resulted in a blood levels 6 times higher than those who ingested Palladone $\mathrm{XL}^{\mathrm{ma}}$ with water (FDA 2005a). Alcohol causes a disruption in the drug release mechanism leading to the entire dose being released at once due to ingestion of ethanol (Johnson et al. 2007). Thus, alcohol induced dose dumping (AIDD) can be defined as the rapid unintended release of a large amount of drug from a MR dosage form resulting from an accidental misuse or from intentional abuse of alcohol with the drug. Co-consumption with alcohol can complicate matters because it may influence the absorption, metabolism and excretion of drugs (Makin \& Williams 2000; Weathermon \& Crabb 1999).

The effect of alcohol (ethanol) in intensifying the pharmacodynamic effects of opioids on the central nervous system (CNS) is well known. In addition to its' clinical effects, studies have demonstrated that moderate consumption of ethanol may pose a risk of drug-drug interactions (Weathermon \& Crabb 1999; Messiha \& Barnes 1979; Linnoila et al. 1979; Palva et al. 1979). Indeed, though the co-ingestion of alcohol is contraindicated on the label, there is a clinical concern that alcohol may be ingested when a patient is on opioids or other centrally acting pain medications (for example, concomitant ingestion of alcohol with Palladone $\mathrm{XL}^{\mathrm{mm}}$ ). Thus, the potential for adverse interactions is enhanced, given the combined clinical effects of alcohol and the drug (Weathermon \& Crabb 1999). Such a scenario would lead to an elevation of side effects like drowsiness or sedation, and depressed respiratory function. Therefore, it is little surprise that the danger of concomitant consumption of alcohol with opioid like pain medication has become a safety concern and attracted attention from regulatory agencies. The relevance here is that the combined pharmacodynamic effect of alcohol and opioids may be even more enhanced by AIDD.

Though prescribing information labels for opioids contain the standard warning that the drug should not be ingested with alcohol, the widespread consumption of alcohol increases this risk. Such findings have been noted in a report by Bernstein et al who highlighted that nearly $42 \%$ of 8774 fatalities recorded in New York City, were caused by an accidental overdose of opioids or opioids and other drugs of abuse with co-ingestion of ethanol (Bernstein et al. 2007). In fact, in countries like the United States where routine consumption of alcoholic beverages is the norm (Serdula et al. 2004), it is no surprise that in another publication, the Drug Abuse Warning Network (DAWN) reported that concomitant use of drugs and alcohol accounted for $14 \%$ of drugrelated emergency department visits in 2012 ((2012) The DAWN Report: highlights of the 2010 Drug Abuse Warning Network (DAWN) findings on drug-related emergency department visits, in: (SAMSHA) Center for Behavioral Health Statistics and Quality, Rockville, MD.). Given that opioids exhibit enhanced solubility in ethanolic solutions, and that some MR dosage forms contain excipients that rapidly dissolve in ethanol, the potential for dose dumping is intensified.

Since the findings with Palladone $\mathrm{XL}^{\mathrm{ma}}$, a few other MR dosage forms have undergone a prescribing information label change to include drug-alcohol interactions. In an in vitro study with Avinza (morphine sulfate extended release capsules), dose dumping was observed when Avinza ${ }^{\circ}(30 \mathrm{mg}$ ) was mixed with $900 \mathrm{~mL}$ of buffer solutions containing either 20 or $40 \%$ ethanol (Avinza Package Insert, Ligand Pharmaceuticals Inc, San Diego, CA). Not surprisingly, the amount and rate of drug release was faster at higher alcohol concentrations. Though an in vivo study was not performed, results of the in vitro experiments were deemed sufficient to show acceleration of drug release from the extended release capsules. In another study with extended release tablets of oxymorphone hydrochloride (Opana $\mathrm{ER}^{\circ}$ ), in vitro experiments did not show rapid drug release in $500 \mathrm{~mL}$ of $0.1 \mathrm{~N} \mathrm{HCl}$ containing either 4, 20 or 40\% ethanol (Opana ER Package Insert, Endo Pharmaceuticals Inc., Chadds Ford, PA). However, the in vivo study indicated that mean AUC was $13 \%$ higher, though not statistically significant, when a single dose of Opana $\mathrm{ER}^{\bullet}(40 \mathrm{mg})$ was co-administered with $240 \mathrm{~mL}$ of $40 \%$ alcohol. No change in AUC was observed at the other concentrations of alcohol administered in the in vivo study (0, 4 and $20 \%)$. Based on these 
findings with Avinza ${ }^{\circ}$ and Opana $\mathrm{ER}^{\circ}$, their product labels contain black-box warnings to state that co-administration of alcohol with the drug may result in a potentially fatal overdose of the drug.

\section{Regulatory considerations}

A memorandum from Ajaz S. Hussain, Ph. D. (who was then Deputy Director, Office of Pharmaceutical Science, CDER, FDA), to members of the Advisory Committee for Pharmaceutical Science (ACPS) was issued on Sept 27, 2005 (FDA 2005b). The purpose of the memo was to set the stage for a 2-day meeting in the following month to discuss some important scientific topics. Two presentations were planned to make the committee aware of a then new concern called "alcohol induced dose dumping" which was defined as the rapid drug release of the entire amount (or significant fraction) of the drug contained in a modified release dosage form due to concomitant consumption with alcohol. Dramatic increases in the release rate of a formulation can pose a significant safety risk to patients. Dose dumping can also affect the efficacy of certain medications. Both of these risks depend on the therapeutic indication and the therapeutic index of a drug.

\section{US FDA's position}

Although FDA has issued a formal guidance that covers dose dumping resulting from the effects of food consumption, only a draft guidance has been issued for alcohol induced dose dumping (AIDD) (CDER/FDA 2002; CDER/FDA 2014). We can infer a position from a collective summary of presentations from and comments made by FDA members. Inferred guidance suggests that a quality-by-design approach should be used to develop formulations that are robust with respect to concomitant consumption of alcohol. The test should involve the use of $0.1 \mathrm{~N} \mathrm{HCl}$ media with differing amounts of ethanol (v/v) added to give the following percentages of ethanol in the media: $0,5,20$, and $40 \%$. In addition to the fasted media (typically $0.1 \mathrm{~N}$ hydrochloric acid), the agency wants to see AIDD in the medium that is validated for release and stability testing of the drug product.

This appears to be a very conservative position, as one of the in vitro conditions ( $40 \%$ alcohol) suggests a reallife situation where one would consume the formulated product with a glass of alcohol equivalent to 80-proof whiskey. It is believed (and it was stated off record) that the Agency's current thinking is that if in vitro testing shows little effect of alcohol throughout this range, then the risk of in vivo dose dumping would be low.

The FDA's Division of Bioequivalence (DBE) now expects information on in vitro dose dumping in the presence of alcohol in its review of ANDAs for certain classes of MR drug products such as opiods (FDA 2005a). This is in response to known safety concerns associated with AIDD that can occur with some MR products. The DBE expects ANDA applicants for MR generics to perform in vitro tests to characterize dose dumping in alcohol if such tests were requested by the Agency for the initial new drug application. More details can be found in FDA's Guidance for Industry, Individual Products Bioequivalence Recommendations Guidances (Anand et al. 2011).

\section{Health Canada's position}

Health Canada's Therapeutic Products Directorate (TPD), the Canadian federal authority that regulates pharmaceutical drugs and medical devices for human use issued a similar warning concerning the potentially deadly interaction between one particular slow-release "opioid" painkiller, Palladone $\mathrm{XL}^{\mathrm{ru}}$, and alcohol in any amount.

The FDA asked Purdue Pharma L.P., to withdraw the drug product from the market in the US. At the same time, the FDA issued a series of alerts about this specific drug product. Canada's TPD took a different approach by extending its warning to all opioids because of similar potential dangers. In 2012, the FDA issued a guidance to prescriber educators to caution patients that the use of CNS depressants, alcohol, or illegal drugs with MR or long-acting opioid analgesics can cause overdose and death.

Both agencies agree on the need for in vitro tests to determine if alcohol impairs the performance of MR dosage forms containing APIs that could present patient risks. In vitro tests could obviate the need for or at least reduce the number of patients who might be put at risk in potentially dangerous clinical studies.

Most, if not all other regulatory agencies throughout the world defer to the FDA's position on this subject.

\section{EU position}

General guidance from the European Medicines Agency (EMA) states that dissolution tests must be developed and validated for all modified-release formulations. The tests must be capable of:

(1) Discriminating between batches with respect to critical manufacturing variables that may have an impact on the desired bioavailability

(2) Showing batch to batch consistency of pivotal clinical, bioavailability, and routine production batches

(3) Determining stability of the relevant release characteristics of the product ((1999) Note for guidance on quality of modified release products: a oral dosage forms, B: transdermal dosage forms 
section 1 (Quality), in, European Medicines Agency Committee for Proprietary Medicinal Products; (2014) Guideline on the pharmacokinetic and clinical evaluation of modified release dosage forms (EMA/CPMP/EWP/280/96 Corr1). in, Committee for Medicinal Products for Human Use (CHMP)).

The concern of the effects of co-consumption of alcohol adds a fourth element in that modified-release formulations must be shown to be robust with respect to the presence of alcohol. Testing for AIDD is performed using the same dissolution medium and apparatus as the validated dissolution method with 0,5 , 10 and $20 \%$ ethanol. If AIDD is observed or suspected, reformulation of the product should be considered ((2014) Guideline on the pharmacokinetic and clinical evaluation of modified release dosage forms (EMA/ CPMP/EWP/280/96 Corr1). in, Committee for Medicinal Products for Human Use (CHMP); EMA, Quality of medicines questions and answers: Part 2, Subchapter: Specific types of product-Need for in-vitro dissolution studies with alcohol for modified release oral products including opioid drug products, in, http://www.ema.europa.eu/ema/index.jsp?curl=pages/regulation/q_and_a/ q_and_a_detail_000072.jsp\#section10). The lack of the $40 \%$ ethanol is an indication of a lack of harmonization between the EMA and the FDA.

The EMA reviewed and provided comments on modified-release pharmaceutical products intended for pain management. Most of these products contain an opioid as the active pharmaceutical ingredient. The EMA stated that "most of these medicines continue to outweigh their risks" and that controlling the release rate within a formulation makes pain management more effective ((1999) Note for guidance on quality of modified release products: a oral dosage forms, B: transdermal dosage forms section 1 (Quality), in, European Medicines Agency Committee for Proprietary Medicinal Products). The EMA specifically stated that due to safety concerns, controlled-release products containing polymethacrylatetriethylcitrate(polymer-plasticizer combination) should be removed from the market and reformulated to make them more robust with respect to alcohol. The EMA also stated that warnings on the interactions of these drugs with alcohol should be made consistent across the class ((1999) Note for guidance on quality of modified release products: a oral dosage forms, B: transdermal dosage forms section 1 (Quality), in, European Medicines Agency Committee for Proprietary Medicinal Products; (2010) European Medicines Agency concludes review of modified-release oral opioids of the WHO level III scale for the management of pain (Press Release)).

\section{Factors that influence AIDD}

Several factors play an important role in enhancing or diminishing the potential for AIDD including: dosage form properties, absorption and metabolism of ethanol, dilution of stomach fluids, and gastric emptying. While studies have discussed the differences in gastric emptying in the fed and fasted states (Higaki et al. 2008), it is intuitive that delayed gastric emptying will increase the propensity of dose dumping, especially in ethanol vulnerable formulations. Indeed, concentrations of ethanol as low as 4 and $10 \%$ have demonstrated prolonged gastric emptying times (Franke et al. 2004). Additionally, consumption of alcohol will alter the amount of stomach fluids. Given that the volume of fluid under fasted conditions is significantly smaller than that under fed conditions (Schiller et al. 2005), gastric dilution effects are expected to be minimal for the former. Dosage form properties also play a critical role in determining the vulnerability of a formulation to AIDD. Most oral MR dosage forms are tablets or capsules, formulated by incorporating the drug in a polymeric matrix. Depending on the polymer type (hydrophobic, hydrophilic or a combination thereof), drug release from an MR type tablet will be governed by the rate of diffusion of liquid into the polymer and consequently, diffusion of drug out of the matrix. A similar strategy is also employed in MR type capsules where a polymer matrix coats an inert bead containing adsorbed drug. These factors should be considered prior to dosage form development and evaluation, whether in vitro or in vivo.

\section{Clinical case studies}

With growing interest in the area of dose dumping due to alcohol, the mid-2000's saw a few clinical studies demonstrate the ruggedness of opioid containing MR dosage forms to AIDD in vivo. In these open-label, single-dose, crossover studies in healthy volunteers, the pharmacokinetics of the opioid from a MR dosage form co-administered with $4 \%$ alcohol (approx. 8 oz of beer), $20 \%$ alcohol (mixed drinks), and 40\% alcohol (neat liquor) under fed and fasted conditions, was assessed.

Table 1 Pharmacokinetic evaluation of Palladone $\mathrm{XL}^{\mathrm{TM}}$ after co-ingestion of alcohol in fasted state (data from reference (FDA 2005a))

\begin{tabular}{lcccc}
\hline Parameter & & Ratio 4 & Ratio 20 & Ratio 40 \\
\hline$C_{\max }$ & Mean & 1 & 2 & 6 \\
& Range & $1-2$ & $1-6$ & $1-16$ \\
\multirow{2}{*}{ AUC } & Mean & 1 & 1 & 1.3 \\
& Range & $0.5-1.9$ & $0.4-1.5$ & $0.6-3.4$ \\
\hline
\end{tabular}




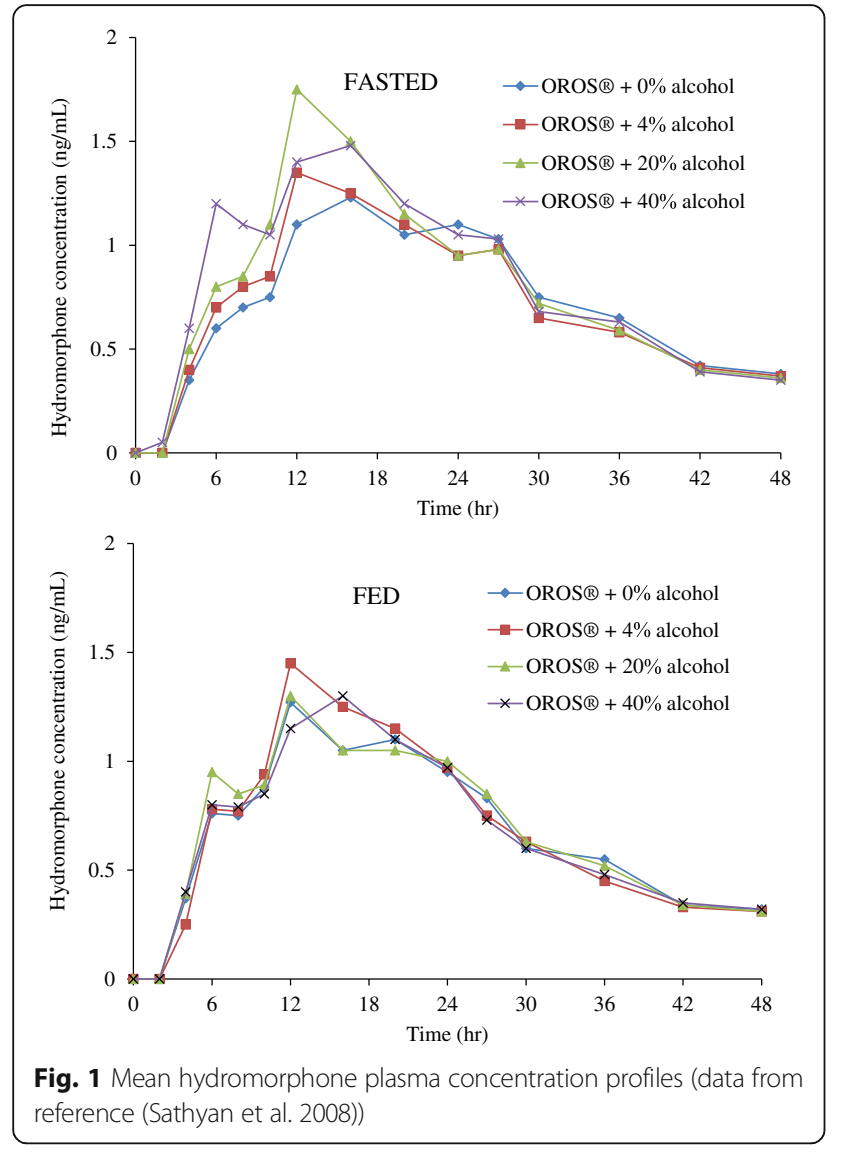

\section{Hydromorphone extended release capsules}

The effect of alcohol co-ingestion with Palladone $\mathrm{XL}^{\mathrm{mm}}$ was evaluated in an open-label, four-arm, cross over pharmacokinetic study under fasted $(n=24)$ and fed $(n=24)$ conditions in adult healthy subjects (FDA 2005a). Prior to administration of the study drug, subjects were administered an opioid antagonist,

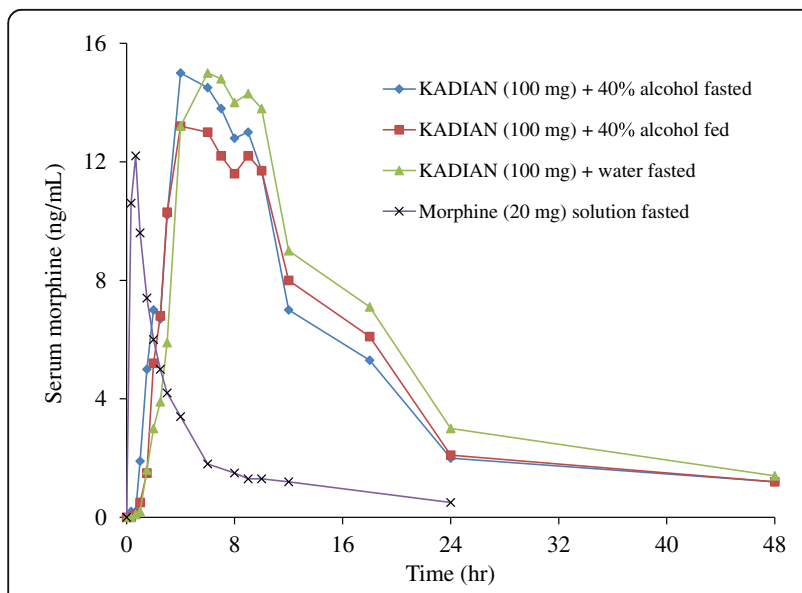

Fig. 2 Mean serum morphine concentration time profiles (data from reference (Johnson et al. 2008))
Table 2 Effect of alcohol on pharmacokinetic parameters of EMBEDA (fasted state) (data from reference (Johnson et al. 2012))

\begin{tabular}{lccc}
\hline Parameter & Ratio 4 & Ratio 20 & Ratio 40 \\
\hline$C_{\max }$ & 1.03 & 1.08 & 2.00 \\
AUC $_{0-\mathrm{t}}$ & 1.01 & 0.98 & 0.97 \\
$\mathrm{AUC}_{\infty}$ & 0.97 & 0.94 & 1.10 \\
\hline
\end{tabular}

naltrexone, to attenuate opioid-induced adverse events, after which they received $12 \mathrm{mg}$ Palladone $\mathrm{XL}^{\mathrm{Tm}}$ (hydromorphone hydrochloride) with $240 \mathrm{~mL}$ water containing $0 \%$ (control), 4,20 or $40 \%$ alcohol in fed or fasted state. The data in Table 1 represent the ratio of $C_{\max }$ values at 4,20 and $40 \%$ alcohol when compared to the control $(0 \%$ alcohol). The results of the study indicated that the effects of alcohol co-ingestion were more pronounced in the fasted state as compared to the fed state where the mean $C_{\max }$ for Ratio 40 was 3.5 with a maximum value of 6 . In comparison, the mean $C_{\max }$ for Ratio 40 in the fasted state was 6 with a maximum value of 16 (Table 1 ).

\section{OROS push-pull containing hydromorphone}

In another study, the effects of AIDD on hydromorphone hydrochloride formulated using OROS Push-Pull, a well known osmotically controlled release delivery system, was investigated in healthy subjects under fed and fasted conditions in an open-label, randomized, four-treatment, four-period, four-sequence, crossover study (Sathyan et al. 2008). Subjects received $16 \mathrm{mg}$ OROS hydromorphone with $240 \mathrm{~mL}$ orange juice or orange juice with 4, 20 or $40 \%$ alcohol in fed (Group 1) or fasted (Group 2) state. While $\mathrm{T}_{\max }$ and $\mathrm{AUC}_{\text {inf }}$ values were similar for both groups (fed and fasted), higher $\mathrm{C}_{\max }$ values were observed with alcohol ingestion across the fed and fasted groups (Fig. 1). The authors attributed the higher $\mathrm{C}_{\max }$ values to the unusually high amount of alcohol (equivalent to 4-8 units of vodka) consumed within 20-30 min, a notably short duration and concluded that the changes in bioavailability of hydromorphone from the OROS technology were minimal.

\section{Morphine sulfate extended release capsules}

Alpharma Pharmaceuticals, the manufacturer of KADIAN (morphine sulfate extended release capsules) carried out an open-label, single-dose, 3-way crossover

Table 3 Effect of ethanol on pharmacokinetic parameters of Remoxy (data from reference (de Kater et al. 2008))

\begin{tabular}{lccc}
\hline Parameter & Ratio 4 & Ratio 20 & Ratio 40 \\
\hline$C_{\max }$ & 0.99 & 0.86 & 1.10 \\
AUC $_{0-\mathrm{t}}$ & 1.00 & 1.05 & 1.14 \\
AUC $_{\infty}$ & 1.00 & 1.06 & 1.14 \\
\hline
\end{tabular}




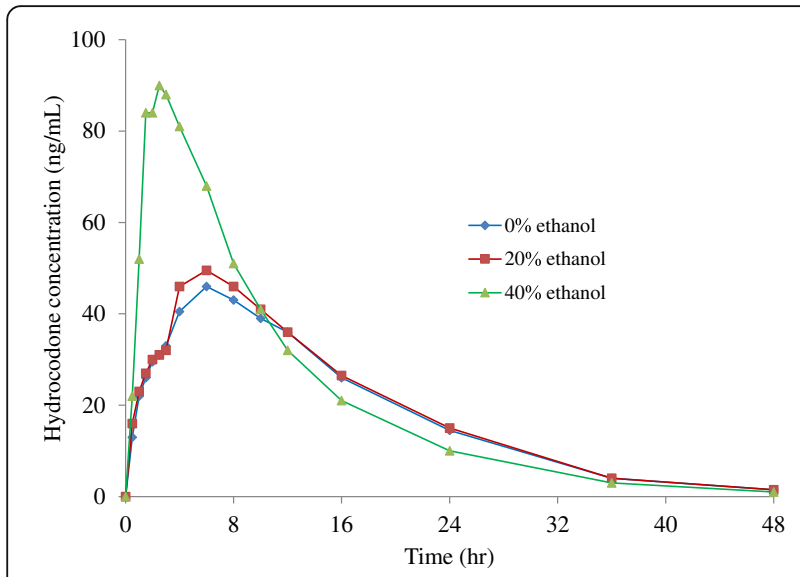

Fig. 3 Mean serum hydrocodone concentration time profiles (data from reference (Farr et al. 2015))

pharmacokinetic study in healthy volunteers using 100 mg KADIAN co-administered with $40 \%$ alcohol in the fasted and fed conditions, and compared the results against $100 \mathrm{mg}$ KADIAN administered with water (Johnson et al. 2008). Additionally, the pharmacokinetics of an oral solution of $20 \mathrm{mg}$ morphine sulfate (immediate release) with water, in the fasted state, was also investigated. As part of common practice in clinical studies with opioids, subjects were administered $50 \mathrm{mg}$ naltrexone hydrochloride (tablet), an opioid antagonist, before and after treatment. From the study results (Fig. 2), the authors concluded that the pharmacokinetics of morphine did not differ significantly between treatment groups and therefore, there was negligible in vivo interaction between KADIAN and alcohol.

In another study on morphine sulfate formulated as EMBEDA extended release capsules $(60 \mathrm{mg})$, bioavailability upon concomitant ingestion of alcohol in healthy subjects was examined under fasted conditions in an open-label, randomized, single-dose, 4-way crossover, 4-sequence drug interaction study. EMBEDA contains pellets of extended release morphine sulfate with sequestered naltrexone hydrochloride core (MS-sNT) and is indicated for the management of chronic, moderate to severe pain (Johnson et al. 2012). The subjects in the study were administered $60 \mathrm{mg}$ MS-sNT with $240 \mathrm{~mL}$ of $0,4,20$ or $40 \%$ alcohol. The alcohol was administered in $60 \mathrm{~mL}$ quantities (shots) in 5 min intervals; with dosage form intake during the first shot. The pharmacokinetic data revealed no drug interaction between morphine in MS-sNT and 4 or $20 \%$ alcohol, i.e. no change in the rate of absorption or extent of exposure (Table 2). Though overall bioavailability of morphine was not affected with co-ingestion of $40 \%$ alcohol (Ratio 40), there was a 2 -fold increase in $\mathrm{C}_{\max }$ and reduction in $\mathrm{T}_{\max }$ from 9 to $4 \mathrm{~h}$ when compared with MS-sent administered with water. Naltrexone levels were unaffected by co-administration of alcohol.

\section{Oxycodone controlled release capsules}

The effects of alcohol on an abuse-resistant formulation of controlled release oxycodone (Remoxy $40 \mathrm{mg}$ capsules) were investigated in a single-center, randomized, four-way crossover study (de Kater et al. 2008).

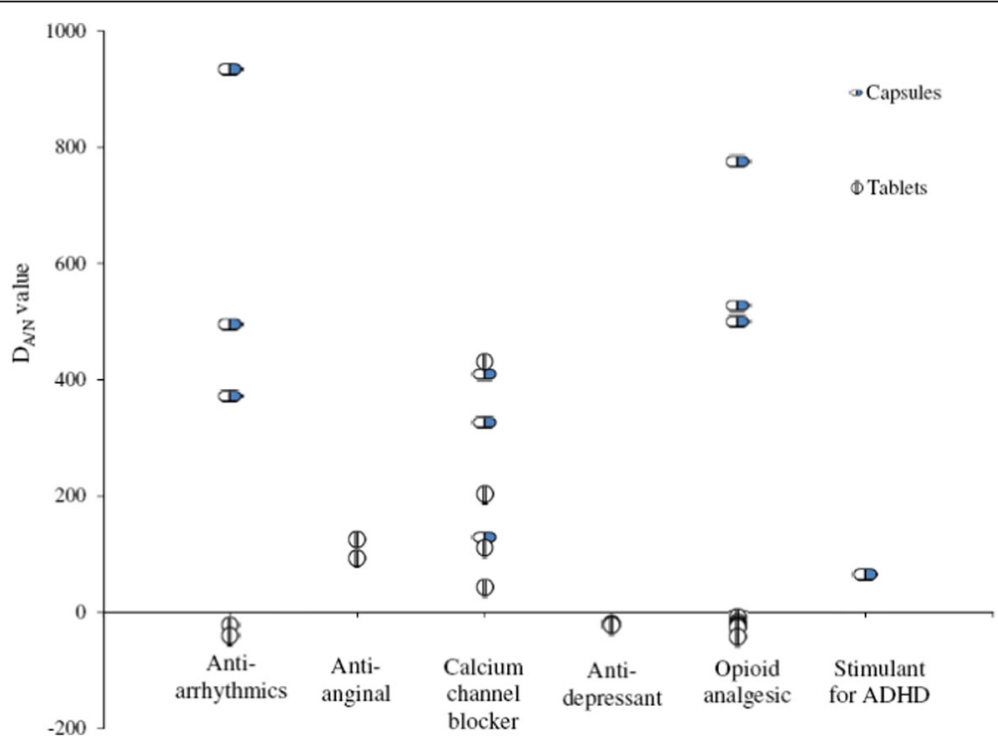

Fig. $4 D_{\text {AN }}$ values at $30 \mathrm{~min}$ in 40 and 20\% alcoholic media (data from reference (Smith et al. 2010)) 


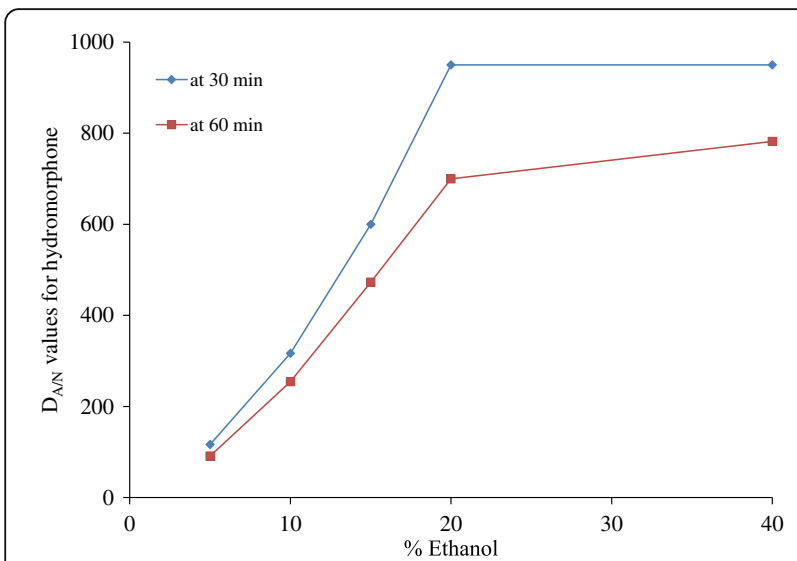

Fig. $5 D_{\text {AIN }}$ values of hydromorphone from once daily capsules in SGF/ethanol (data from reference (Walden et al. 2007))

Each subject ingested a single capsule of Remoxy $40 \mathrm{mg}$ during each of four treatment sequences that were separated by a $96-\mathrm{h}$ washout period.

Treatment 1: Remoxy $40 \mathrm{mg}$ capsule + water

Treatment 2: Remoxy $40 \mathrm{mg}$ capsule $+4 \% /$ ethanol ("Low Proof")

Treatment 3: Remoxy $40 \mathrm{mg}$ capsule $+20 \%$ ethanol ("Medium Proof")

Treatment 4: Remoxy $40 \mathrm{mg}$ capsule $+40 \%$ ethanol ("High Proof")

From the values in Table 3, except for a slight drop in $\mathrm{T}_{\max }$, co-ingestion of $4 \%$ alcohol had no effect on pharmacokinetic parameters. Though a slight decrease in $\mathrm{C}_{\max }$ was observed with $20 \%$ alcohol while administration of $40 \%$ alcohol caused a slight increase in pharmacokinetic parameters, the formulation maintained its controlled release properties.

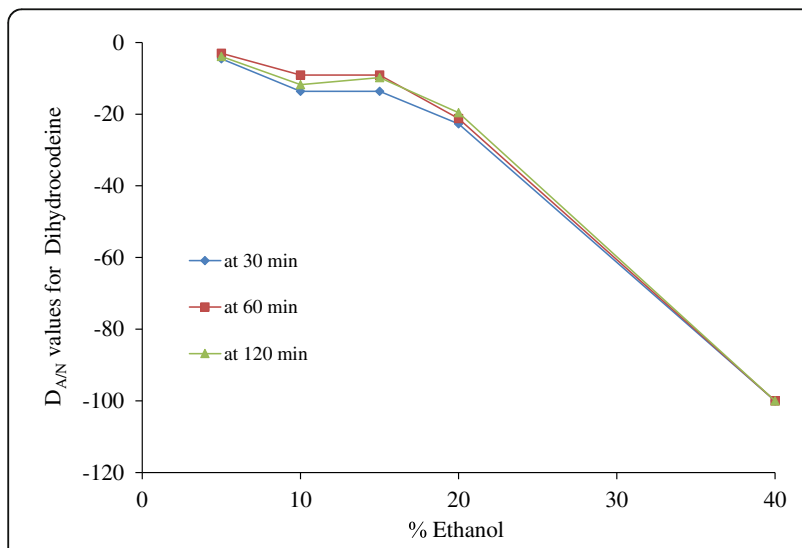

Fig. $6 D_{\text {AIN }}$ value of dihydrocodeine tablets at $\mathrm{pH} 6.5$ phosphate in buffer/ethanol (data from reference (Walden et al. 2007))

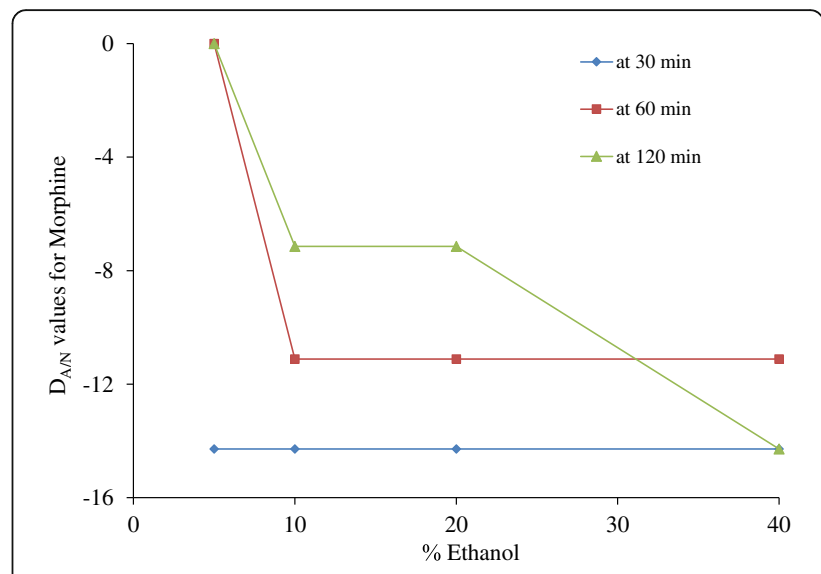

Fig. $7 D_{A / N}$ value of morphine capsules in phosphate buffer/ethanol (data from reference (Walden et al. 2007))

\section{Hydrocodone extended release capsules}

The effect of alcohol on an oral, extended-release formulation of hydrocodone was evaluated in a threetreatment, three-period crossover study in healthy volunteers (Farr et al. 2015). In the first period, $50 \mathrm{mg}$ hydrocodone was administered with $240 \mathrm{~mL}$ of either $40 \%$ alcohol/orange juice, $20 \%$ alcohol/orange juice, or orange juice alone, after an overnight fast. Similar to other clinical studies with opioids, $50 \mathrm{mg}$ naltrexone was administered approximately $12 \mathrm{~h}$ (with a light snack) and $2 \mathrm{~h}$ (fasted) prior to, and $10 \mathrm{~h}$ (with a light snack) after dosing of the study drug. Subjects received the alternative treatments according to a randomization code during the second and third treatment periods, with a 4-5 day separation between treatments. Similar exposures were obtained with 0 and $20 \%$ alcohol. With $40 \%$ alcohol, a shorter $\mathrm{T}_{\max }$ with higher $\mathrm{C}_{\max }$ and AUC

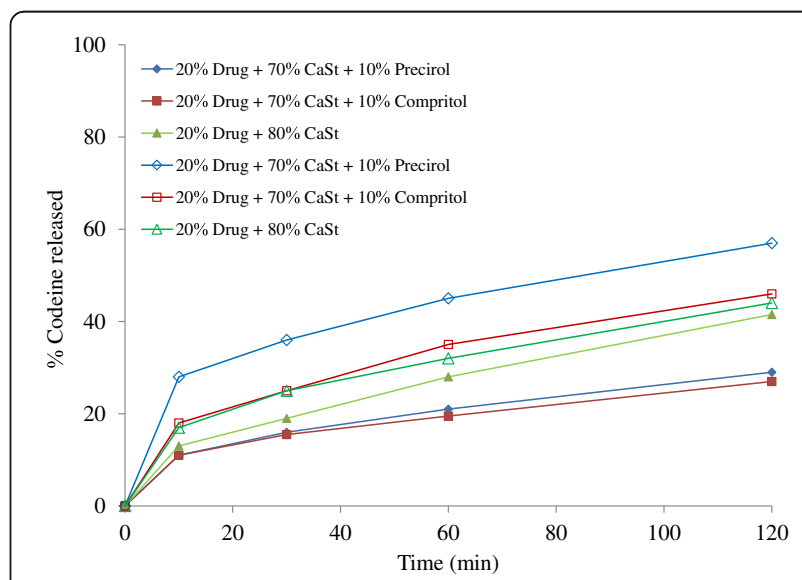

Fig. 8 Effect of ethanol concentration on release of codeine from hot melt extruded pellets (closed legends $=0 \%$ ethanol, open legends $=40 \%$ ethanol) (data from reference (Jedinger et al. 2015)) 
Table $4 D_{\text {A/N }}$ values of tramadol from Tridural ${ }^{\text {TM }}$ Tablets, Ultram ${ }^{\oplus}$ ER Tablets, and T-long ${ }^{\oplus}$ Capsules after 4 h in 20 and 40\% ethanolic media (data from reference (Traynor et al. 2008))

\begin{tabular}{|c|c|c|}
\hline Formulation & $D_{\text {A/N }}$ value ( $20 \%$ ethanol) & $D_{\text {A/N }}$ value ( $40 \%$ ethanol) \\
\hline Tridural $^{\mathrm{TM}}$ Tablets & -27.55 & -20.77 \\
\hline Ultram ${ }^{\oplus}$ ER Tablets & 37.09 & 214.21 \\
\hline T-long ${ }^{\circledast}$ Capsules & 73.81 & 113.68 \\
\hline
\end{tabular}

values was observed (Fig. 3). The authors concluded that while no dose dumping was seen, concomitant ingestion of alcohol with the hydrocodone extended release capsules was not advised.

Two key points/lessons learned from the above clinical studies:
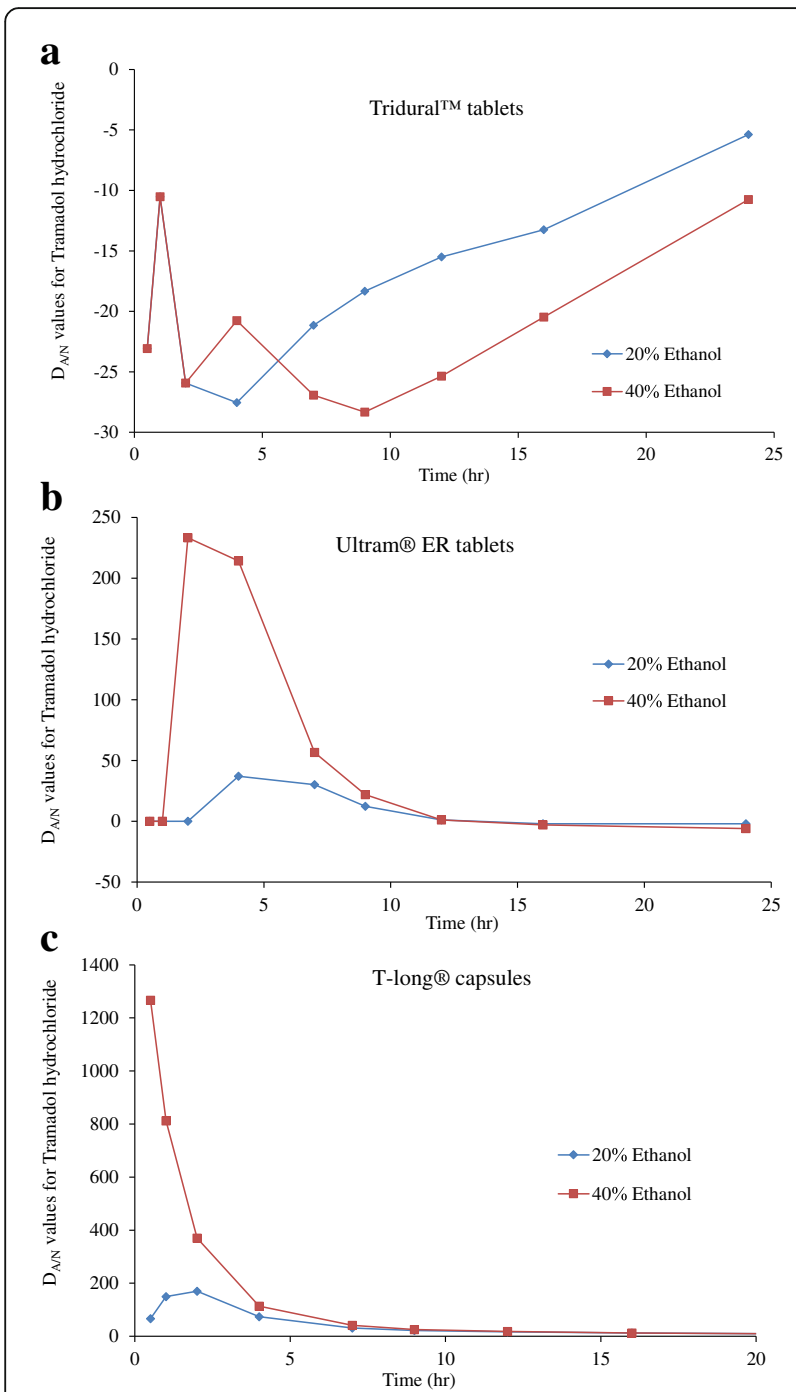

Fig. 9 The effect of ethanol concentration on the $D_{A / N}$ values of tramadol hydrochloride for three different formulations. (data from reference (Traynor et al. 2008))
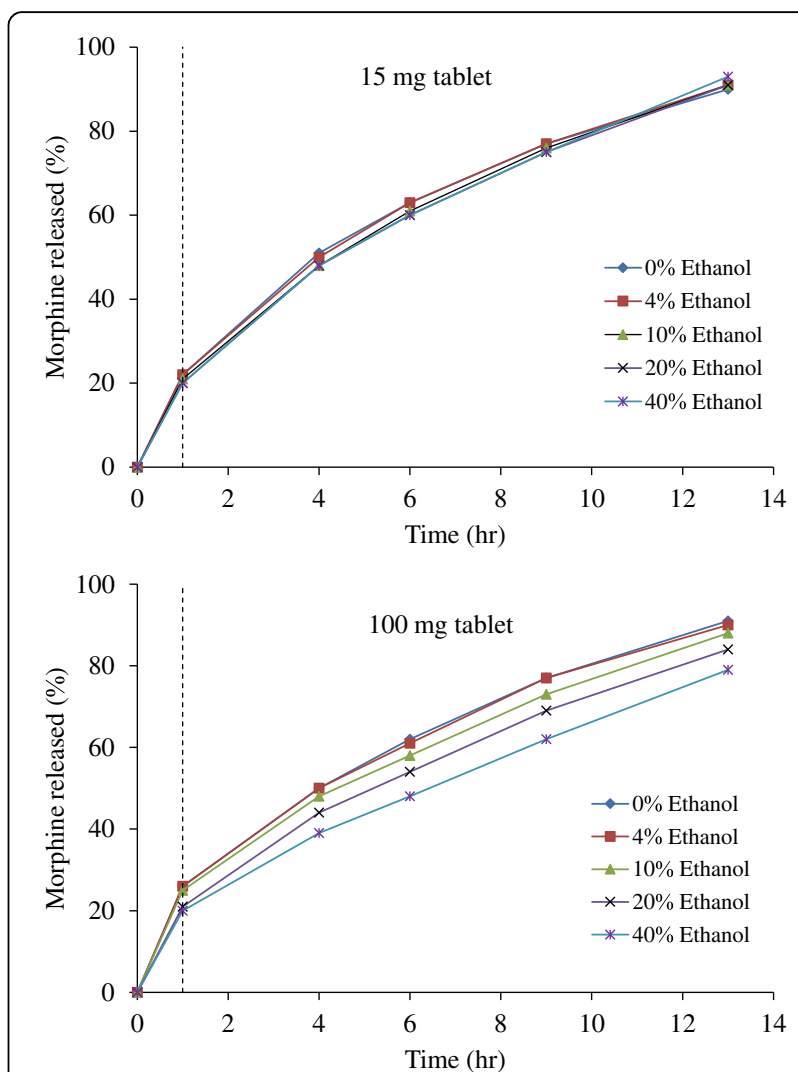

Fig. 10 Morphine sulfate release over time from SR tablets in ethanol (dotted line indicates a change from acid to buffered conditions) (data from reference (Barkin et al. 2009))

(a) Given the side-effects of ingesting $40 \%$ alcohol as multiple 'shots' immediately, the authors feel that a clinical study design should provide a reasonable time-frame for ingestion of alcohol. For instance, in their study with hydromorphone, subjects were advised to consume the orange juice-alcohol solutions slowly, but within $30 \mathrm{~min}$, to avoid vomiting (Sathyan et al. 2008). Such type of design may reduce study drop-out rates and thereby, associated costs and timelines.

(b) To reduce adverse events before dosing the opioid drug, the authors agree with the sponsors' approach of administering naltrexone, an opioid receptor antagonist (Johnson et al. 2008; Farr et al. 2015).

\section{In vitro case studies}

Multiple cases studies have been presented in the literature concerning AIDD. Retrospective studies have been conducted for AIDD where existing products on the market have been tested on their potential to dose dump in different levels of alcohol. Other studies have focused on formulation based comparisons where certain extended release excipients have been shown to be more vulnerable to dose dumping than others. A summary of some of these studies is presented. 


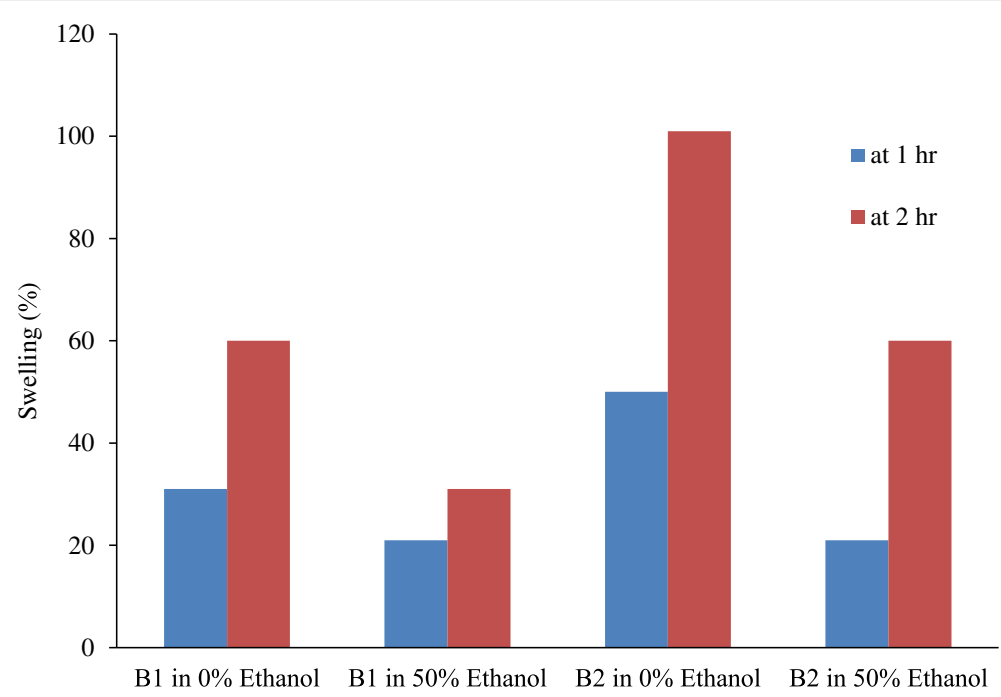

Fig. 11 Effect of alcohol on the swelling property of Carbopol 71G tablets and matrices (data from reference (Emeje et al. 2008))

\section{Opioids and other centrally acting drugs \\ FDA ethanol study}

The U.S. Food and Drug Administration published a paper that compared various oral modified-release products from different therapeutic areas (Smith et al. 2010). The percentages of ethanol used in the studies were 5, 20 and $40 \%$ with the USP listed dissolution medium and methodology. The dissolution value $\left(\mathrm{D}_{\mathrm{A} / \mathrm{N}}\right)$ reported used the relative change in the amount of dissolution in the alcoholic medium compared to the values in the purely aqueous medium at a specific time point.

$$
\mathrm{D}_{\mathrm{A} / \mathrm{N}}=\frac{100 *\left(\mathrm{D}_{\mathrm{A}}-\mathrm{D}_{\mathrm{N}}\right)}{\mathrm{D}_{\mathrm{N}}}
$$

Where $\mathrm{D}_{\mathrm{A}}$ is the percent drug dissolved in alcoholic medium and $D_{N}$ is the percent drug dissolved in the "non-

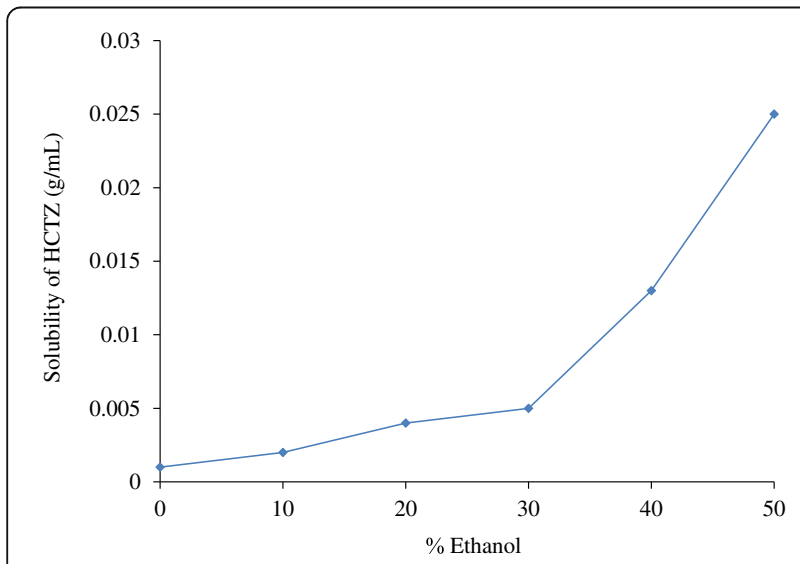

Fig. 12 Effect of ethanol concentration on the solubility of HCTZ in different hydro-alcoholic media (data from reference (Emeje et al. 2008)) alcoholic" medium. These values were reported at $30 \mathrm{~min}$ and also plotted versus time through $8 \mathrm{~h}$. Positive values indicate a greater release in alcohol and negative values indicate a slower release.

All capsules studied gave positive $\mathrm{D}_{\mathrm{A} / \mathrm{N}}$ values for the $40 \%$ ethanol at 30 min whereas most tablets had negative values (Fig. 4). Values over 900 were observed indicating $>900 \%$ release compared to the non-alcohol medium. Most of the capsules were conventional beadsor pellet-filled hard gelatin capsules except for the opioid analgesics, which were made by melt extrusion technology or contained a mixture of immediate release and enteric-coated delayed release pellets. Those tablets that gave high $D_{\mathrm{A} / \mathrm{N}}$ values contain hypromellose (HPMC).

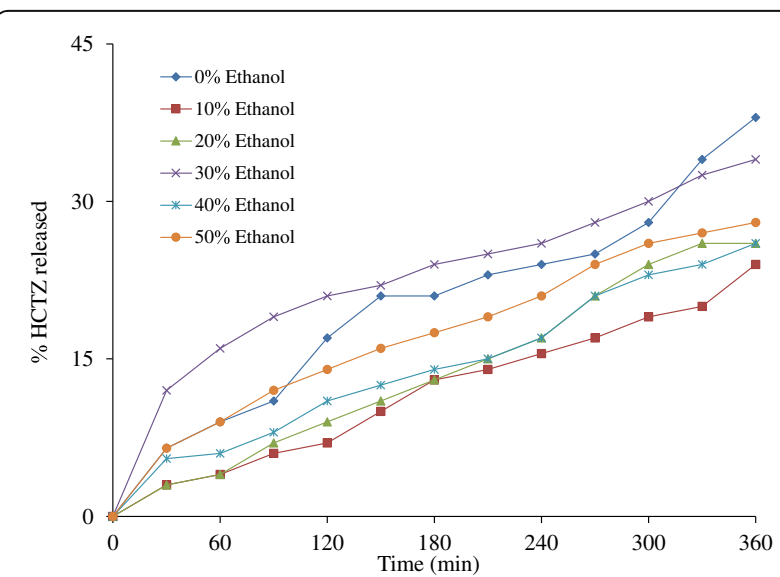

Fig. 13 Effect of ethanol concentration on the release profile of HCTZ from Carbopol71G tablet (data from reference (Emeje et al. 2008)) 

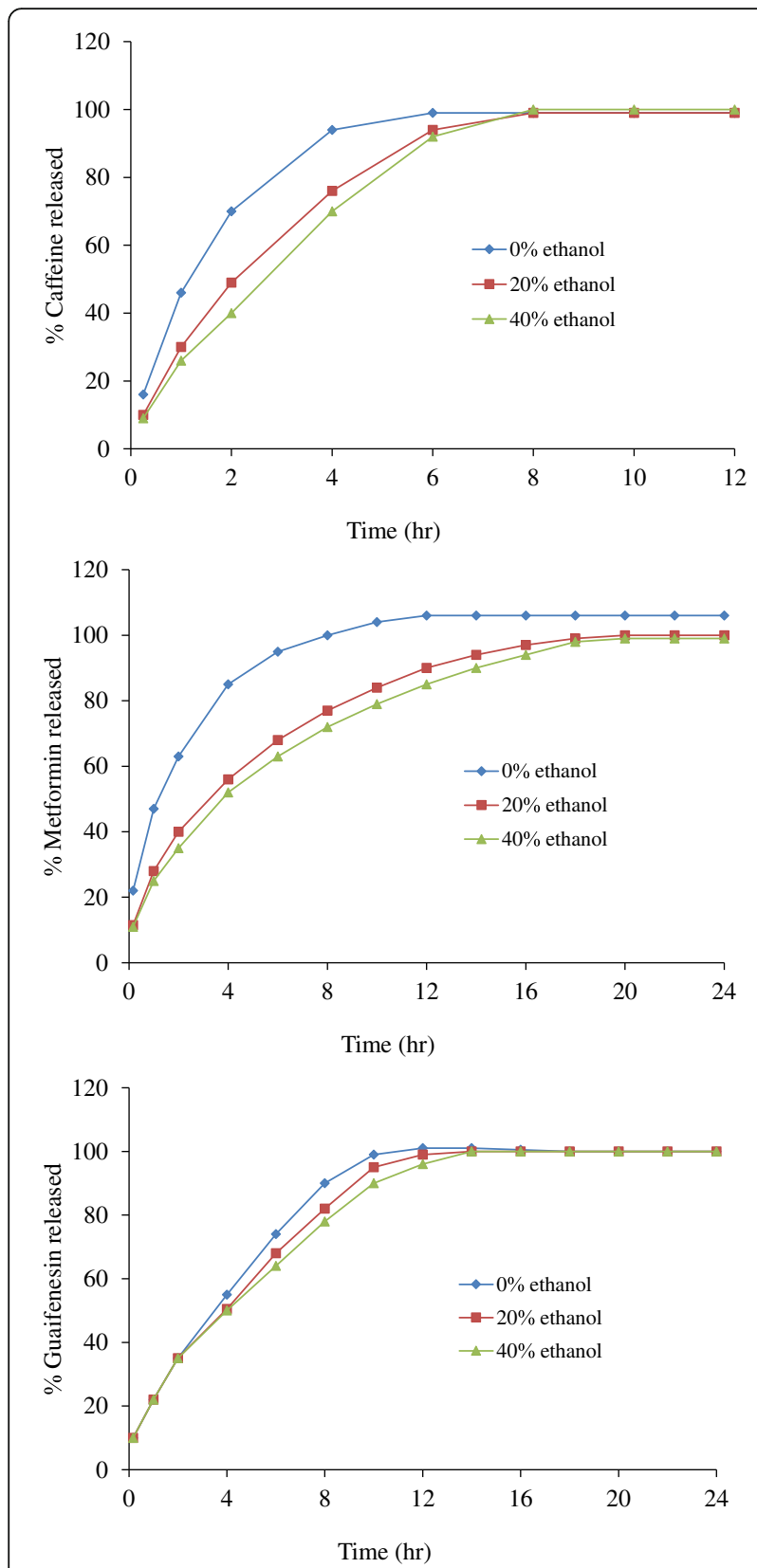

Fig. 14 Effect of alcohol on release of caffeine, metformin and guaifenesin from Carbopol 971G based tablets (data from reference ((2011) Effect of Alcohol on the Drug Dissolution Properties of Tablets Formulated with Carbopol ${ }^{\circledR *}$ Polymers, Lubrizol Technical Data Sheet 793))

in vivo. Three to four time points were sampled for the first hour followed by the 2-h time point. Five of the products were tested at $5,10,15,20,25,30,35$ and $40 \%$ ethanol while the other four products were tested at 4 , 16, 24, 32 and $40 \%$ ethanol.

The results for most of the products indicated a negligible effect of ethanol on the release. One product, Palladone SR capsule, which utilizes a coated bead technology demonstrates a slower release at low levels of alcohol $(5-15 \%)$ and a higher release at high levels of alcohol (35-40\%) when compared to the control $(0 \%)$ release rate (Figs. 5, 6 and 7). $\mathrm{D}_{\mathrm{A} / \mathrm{N}}$ values greater than 100 are considered to be a significant increase in drug release.

Perhaps the most interest aspect of this paper is the discussion about in vivo alcohol exposures. A strong case is made that in-vitro studies should be for a maximum time of $2 \mathrm{~h}$ to mimic in vivo physiology. Six in vivo studies were cited supporting this statement that discuss fasted and fed gastric emptying, alcohol absorption and alcohol metabolism as well as dilution effects by gastric fluids and saliva. This prompts questions as to whether clinical study designs reflect real life scenarios.

\section{Codeine hot melt extruded pellets}

Various formulations were investigated using hot-melt extruded pellets containing codeine phosphate (lower solubility in ethanol) and paracetamol (highly soluble in ethanol, see Paractemol hot melt extruded pellets section) were examined for resistance to alcohol dose dumping (Jedinger et al. 2015). The formulations contained calcium stearate as matrix carrier and two ethanol- and water-insoluble solid lipids, glycerol distearate and glycerol dibehenate. Characterization of the powder substances and pellets were performed including DSC, FT-IR spectroscopy, solubility, media uptake, contact angle and pellet morphology. Dissolution results were presented in $0 \%$ ethanol in $0.1 \mathrm{~N} \mathrm{HCl}, 20 \%$ ethanol in $0.1 \mathrm{~N} \mathrm{HCl}$ and $40 \%$ ethanol in $0.1 \mathrm{~N} \mathrm{HCl}$. There were three formulations prepared that all contained $20 \%$ active ingredient. These formulations are:

(1) $70 \%$ CaSt with $10 \%$ glycerol distearate (Precirol),

(2) $70 \%$ CaSt with $10 \%$ glycerol dibehenate (Compritol), and

(3) $80 \%$ Calcium Stearate (CaSt),

The dissolution results of the codeine phosphate in $0 \%$

\section{Extended release opioids}

Nine extended-release opioid products containing dihydrocodeine, morphine, oxycodone, hydromorphone, and tramadol were tested for AIDD over $2 \mathrm{~h}$ (Walden et al. 2007). The 2-h period is expected to be representative of the most extreme conditions likely to be encountered ethanol in $0.1 \mathrm{~N} \mathrm{HCl}$ and $40 \%$ ethanol in $0.1 \mathrm{~N} \mathrm{HCl}$ are presented in Fig. 8. Codeine phosphate has a greater release after $2 \mathrm{~h}$ in $0.1 \mathrm{~N} \mathrm{HCl}$. The formulation with CaSt only has the highest release in $0.1 \mathrm{~N} \mathrm{HCl}$ and only a slight increase in $40 \%$ ethanol. 

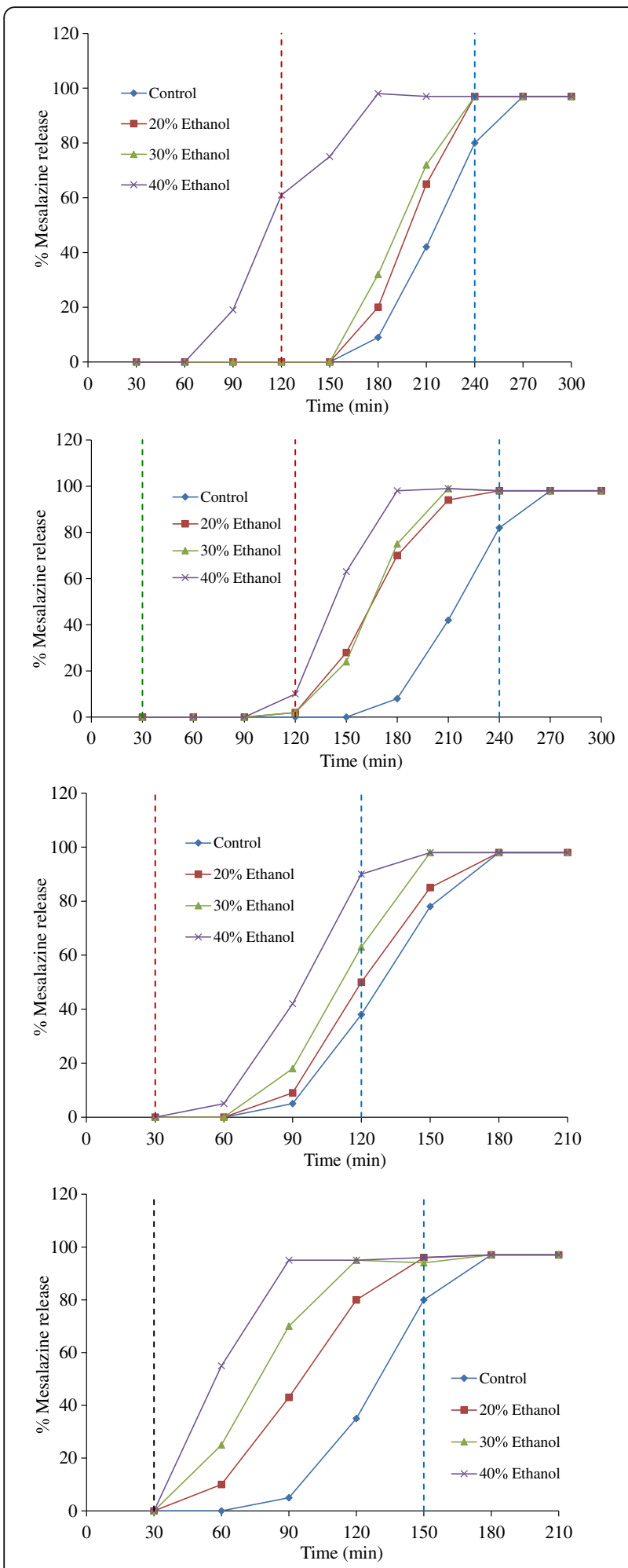

Fig. 15 Dissolution of Salofalk tablets (red dotted line represents change from $0.1 \mathrm{M} \mathrm{HCl}$ with ethanol to $\mathrm{pH} 6.8$ phosphate buffer, blue dotted line represents change from $\mathrm{pH} 6.8$ phosphate buffer to $\mathrm{pH} 7.4$ phosphate buffer, green dotted line represents change from $0.1 \mathrm{M} \mathrm{HCl}$ with ethanol to $0.1 \mathrm{M} \mathrm{HCl}$ with no ethanol, black dotted line represents change from $0.1 \mathrm{M} \mathrm{HCl}$ with ethanol to $\mathrm{pH} 6.8$ phosphate buffer where only the first 15 min contains ethanol equivalent to half the concentration in acid) (data from reference (Fadda et al. 2008))

\section{Three tramadol formulations evaluated}

Three commercially available formulations of tramadol were evaluated for AIDD using full dissolution profiles at 0,20 and $40 \%$ ethanol using the same dissolution method (Traynor et al. 2008). The three formulations had three various sensitivities to alcohol that depended on their excipient's solubility in alcohol (Table 4). The main excipient in T-long ${ }^{\circ}$ capsules, Eudragit ${ }^{\circ}$ NE30D, is soluble in ethanol and showed AIDD in both 20 and $40 \%$ ethanol dissolution media. The two main excipients in Ultram ${ }^{\circ}$ ER Tablet, povidone and ethylcellulose, are also soluble in alcohol. This formulation has an increased release profile in $40 \%$ alcohol medium when compared to the control ( $0 \%$ alcohol) medium. Lastly, the Tridural ${ }^{\circ}$ Tablet contains Kollidon SR. This excipient is a physical mixture of polyvinylacetate $(80 \%)$ that is insoluble in ethanol, and povidone (20\%), that is soluble in alcohol. The product shows a decrease in release rate in both 20 and 40\% ethanol media (Fig. 9) (Traynor et al. 2008).

\section{Effect of ethanol on morphine sulfate $S R$}

Dissolution AIDD studies were performed on Oramorph SR, 15, 30, 60 and $100 \mathrm{mg}$ strengths at 4, 10, 20 and 40\% ethanol concentration (Barkin et al. 2009). The dissolution for this product involves a two stage process where the product is run with $500 \mathrm{~mL} 0.1 \mathrm{~N} \mathrm{HCl}$ dissolution media for $1 \mathrm{~h}$ in USP Apparatus I. The basket is removed and transferred to the second stage media, $\mathrm{pH} 7.5$ phosphate buffer and run for $12 \mathrm{~h}$ (Fig. 10).

Results of the testing show similar release rates in the $4 \%$ alcohol media compared to the control without alcohol for the two lower strengths, 15 and $30 \mathrm{mg}$. The two higher strengths have slower release rates as the percentage of alcohol increases. These results indicate that this product is not vulnerable to dose dumping in ethanol.

\section{Other (Non-Opioid) drugs}

\section{Hydro-alcoholic media and the excipient polyacrylic acid} polymer (Carbopol 71G)

This paper looks at the effect of various levels of alcohol $(0,10,20,30,40$ and $50 \%)$ on tablet swelling and release of the drug hydrochlorothiazide (HCTZ) from a 50-50 mixture of carbopol $71 \mathrm{G}$ extended release matrix (Emeje et al. 2008). Except for 30\% ethanol media, all ethanolic media show a decrease in HCTZ release over $6 \mathrm{~h}$ when compared to the control $(0 \%)$ media. 

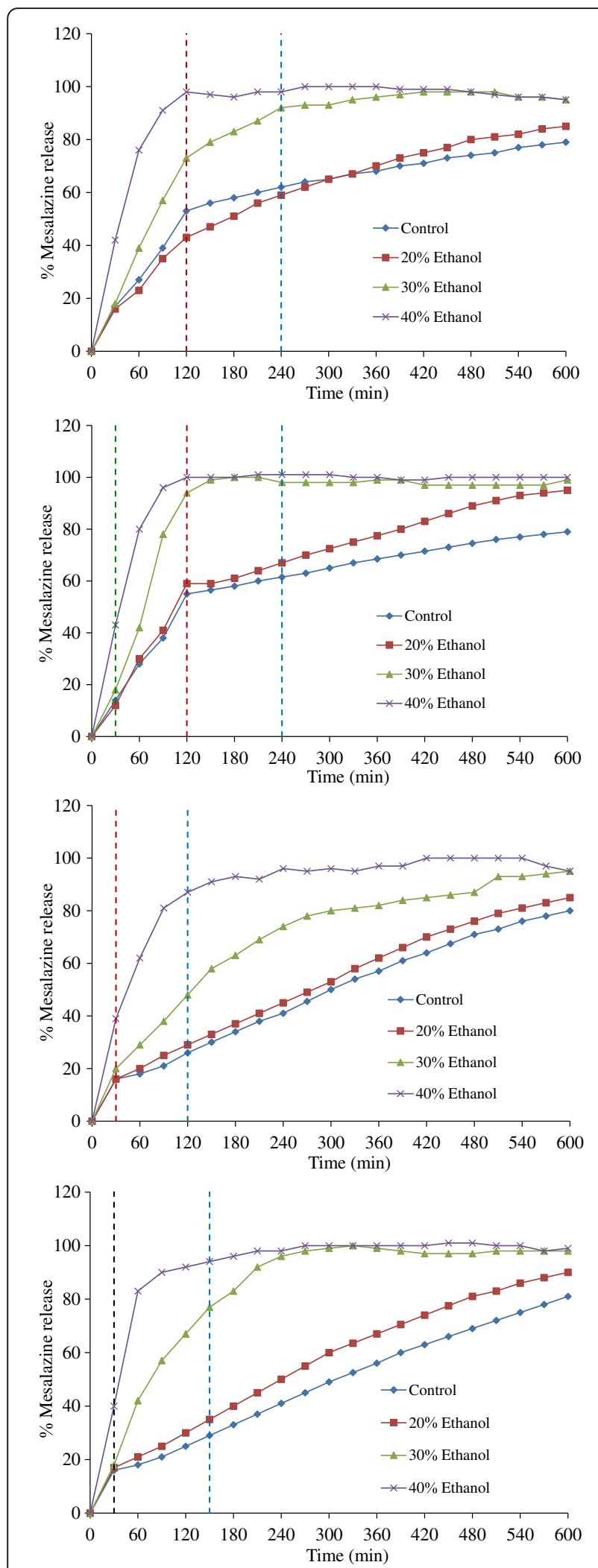

Fig. 16 Dissolution of Pentasa tablets (red dotted line represents change from $0.1 \mathrm{M} \mathrm{HCl}$ with ethanol to $\mathrm{pH} 6.8$ phosphate buffer, blue dotted line represents change from $\mathrm{pH} 6.8$ phosphate buffer to $\mathrm{pH} 7.4$ phosphate buffer, green dotted line represents change from $0.1 \mathrm{M} \mathrm{HCl}$ with ethanol to $0.1 \mathrm{M} \mathrm{HCl}$ with no ethanol, black dotted line represents change from $0.1 \mathrm{M} \mathrm{HCl}$ with ethanol to $\mathrm{pH} 6.8$ phosphate buffer where only the first 15 min contains ethanol equivalent to half the concentration in acid) (data from reference (Fadda et al. 2008))

HCTZ has an increased solubility with higher percentage of ethanol. Therefore, the decreased release rate in alcohol is caused by the polymer-alcohol interactions than the drug solubility in the dissolution medium (Figs. 11, 12 and 13).

\section{Hydro-alcoholic media and the ethanol resistant excipient polyacrylic acid polymer (Carbopol971G)}

The effect of 0,20 and $40 \%$ alcohol on the dissolution of caffeine, metformin hydrochloride and guaifenesin tablets formulated using Carbopol 971G polymer was studied. When compared to $0.1 \mathrm{~N} \mathrm{HCl}$ ( $0 \%$ ethanol), low solubility of caffeine and metformin hydrochloride in ethanol led to slower release from dissolution media containing 20 or $40 \% \mathrm{v} / \mathrm{v}$ alcoholic media. For guaifenesin, slight slowing of drug release was noted with 10\% (but not 20\%) Carbopol 971G polymer (Fig. 14) ((2011) Effect of Alcohol on the Drug Dissolution Properties of Tablets Formulated with Carbopol ${ }^{* *}$ Polymers, Lubrizol Technical Data Sheet 793).

\section{Four ethanol exposure scenarios for mesalazine ER}

Three mesalazine extended release products were tested under four different concentrations and durations of alcohol and $\mathrm{pH}$ medium (Fadda et al. 2008). Two of the mesalazine products studied are enteric coated and designed to release in the distal end of the GI tract while the third product was more of a traditional extended-release product using ethyl cellulose. This paper considers the pattern of alcohol distribution in the GI tract and how they vary under different physiological states. The products were exposed to a $\mathrm{pH}$ transition to simulate different regions of the GI tract. The tablets were transferred from one medium to another. The percentages of alcohol studied were 0 (control), 5, 20, 30 and $40 \%$. The data for the $5 \%$ alcohol was not presented as it was similar to the control.

The four scenarios lasting a total of $10 \mathrm{~h}$ were:

(1) $0.1 \mathrm{~N} \mathrm{HCl}$ with ethanol for $2 \mathrm{~h}$ followed by $\mathrm{pH} 6.8$ phosphate for $2 \mathrm{~h}$ then $\mathrm{pH} 7.4$ phosphate 


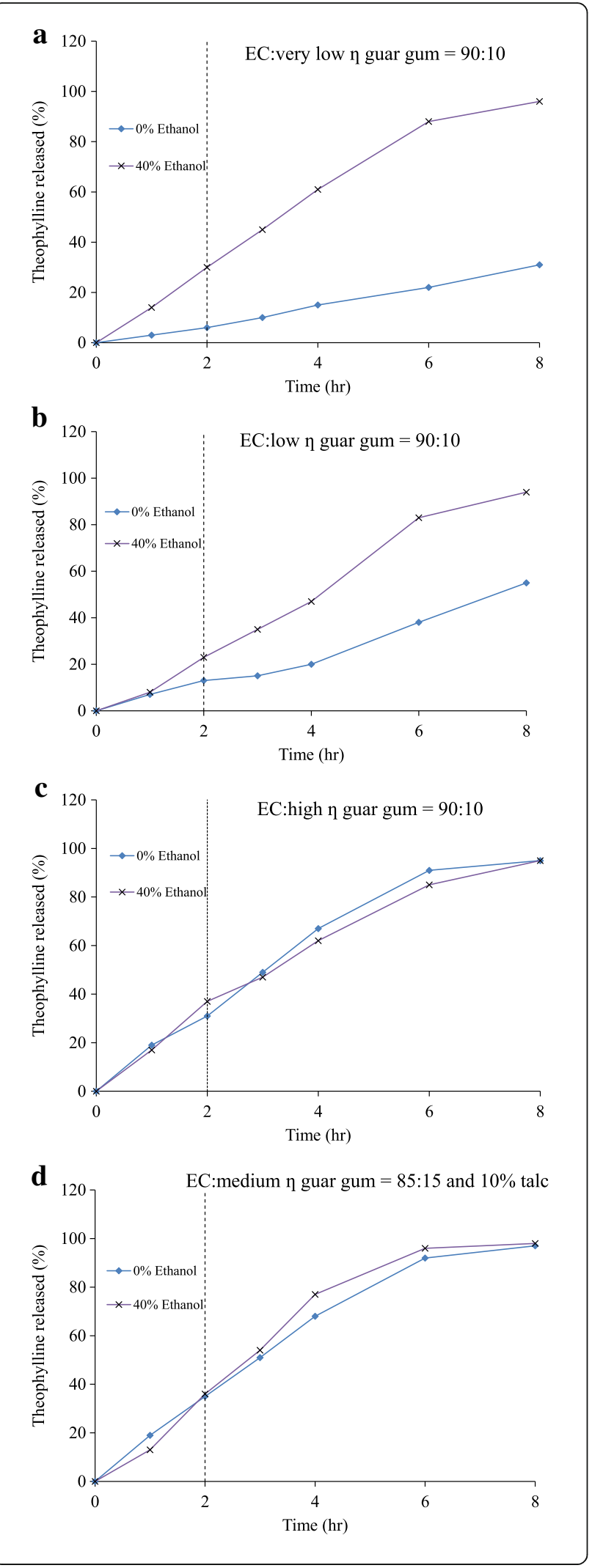

Fig. 17 Effect of ethanol on release of theophylline from $\mathrm{pH} 7.4$ phosphate buffer (dotted line indicates a change from acid to buffered non-ethanolic conditions) (data from reference (Rosiaux et al. 2013))

(2) $0.1 \mathrm{~N} \mathrm{HCl}$ with ethanol for 30 min followed by $0.1 \mathrm{~N} \mathrm{HCl}$ with no ethanol for $90 \mathrm{~min}$ followed by $\mathrm{pH} 6.8$ phosphate for $2 \mathrm{~h}$ then $\mathrm{pH} 7.4$ phosphate

(3) $0.1 \mathrm{~N} \mathrm{HCl}$ with ethanol for $30 \mathrm{~min}$ followed by $\mathrm{pH} 6.8$ phosphate for $2 \mathrm{~h}$ then $\mathrm{pH} 7.4$ phosphate

(4) $0.1 \mathrm{~N} \mathrm{HCl}$ with ethanol for $30 \mathrm{~min}$ followed by $\mathrm{pH} 6.8$ phosphate for $2 \mathrm{~h}$ (first 15 min containing ethanol equivalent to half the concentration in acid) followed by $\mathrm{pH}$ 7.4 phosphate

Alcohol was observed to have a significant impact on the release profile of all three products. For the enteric coated products, exposure to alcohol during the acid stage caused the coating integrity to be compromised and the drug to release earlier than designed. The four scenarios did show different sensitivities to alcohol. The ethylcellulose product had a significant increase in the early stage of dissolution for both the 30 and $40 \%$ alcohol when compared to the control (Figs. 15 and 16).

\section{Ethanol resistant polymeric films containing theophylline}

Dissolution AIDD studies were performed on extended release theophylline formulations contains ethylcellulose and very low, low, medium and high viscosity guar gums at 0 , and $40 \%$ ethanol concentrations (Rosiaux et al. 2013). The dissolution for this product involves a two stage process where the product is run with $900 \mathrm{~mL}$ $0.1 \mathrm{~N} \mathrm{HCl}$ dissolution media for $2 \mathrm{~h}$ in USP Apparatus II. Complete media change occurred to the second stage media, $\mathrm{pH} 7.4$ phosphate buffer and run for $6 \mathrm{~h}$ more (Fig. 17).

The formulation process coated theophylline matrix cores using a fluidized bed coater with different

Table $\mathbf{5}$ Influence of ethanol on the relative saturated solubility of three drugs in different media (data from reference (Levina et al. 2007))

\begin{tabular}{llllll}
\hline Drug & \multicolumn{2}{l}{$\begin{array}{l}\text { \% ethanol } \\
\text { in water }\end{array}$} & & \multicolumn{2}{l}{$\begin{array}{l}\text { \% ethanol in phosphate } \\
\text { buffer pH 6.5 (with 1\% SLS) }\end{array}$} \\
\cline { 2 - 3 } \cline { 5 - 6 } & $5 \%$ & $40 \%$ & & $5 \%$ & $40 \%$ \\
\hline felodipine & 2.5 & 1245 & & 0.89 & 5.39 \\
gliclazide & 12 & 11.18 & - & - \\
metformin $\mathrm{HCl}$ & 0.84 & 0.66 & - & - \\
\hline
\end{tabular}




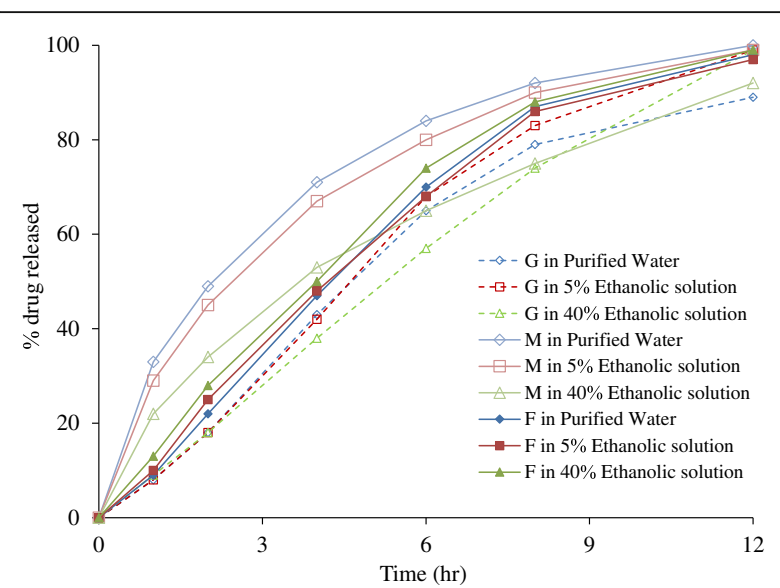

Fig. 18 Release profiles of gliclazide $(G)$, metformin $(M)$ and felodipine (F) from HPMC ER matrices in ethanolic media (data from reference (Levina et al. 2007))

ethylcellulose:guar gum blends. Additional formulation experiments were performed on film properties, addition of anti-tacking agents, curing and stability studies.

Results of the dissolution testing show similar release rates in the $40 \%$ alcohol media compared to the control without alcohol for the medium and high viscosity guar gum coatings. The two lower viscosity guar gum coating have accelerated release rates in the $40 \%$ alcohol medium. These results indicate that the higher viscosity process is not vulnerable to dose dumping in ethanol.

\section{Hydro-alcoholic media and hypromellose (HPMC) matrix systems}

The influence of hydro-alcoholic media on HPMC matrix formulations of three different drugs (felodipine, gliclazide and metformin) that vary in aqueous and

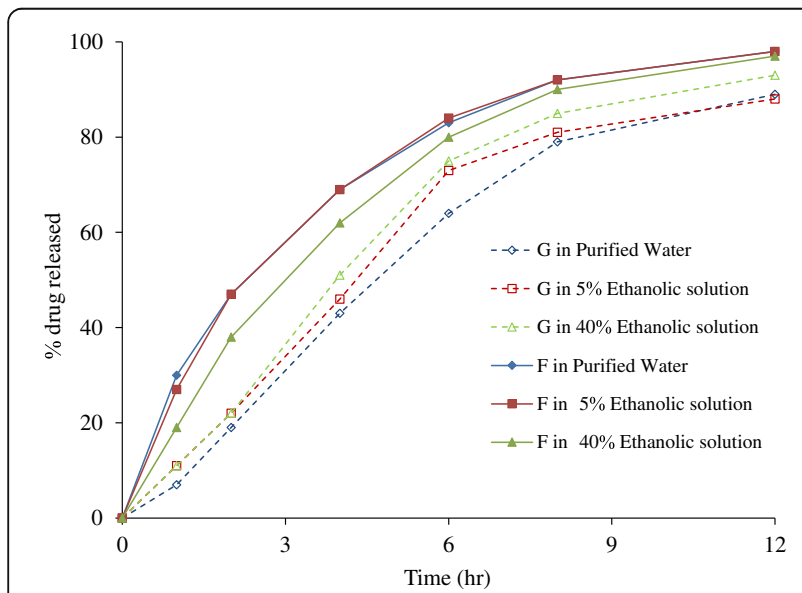

Fig. 19 Effect of $1 \mathrm{~h}$ exposure of HPMC ER matrices to media containing 0,5 or $40 \% \mathrm{v} / \mathrm{v}$ ethanol on release profiles of gliclazide (G) and felodipine (F) (data from reference (Levina et al. 2007))

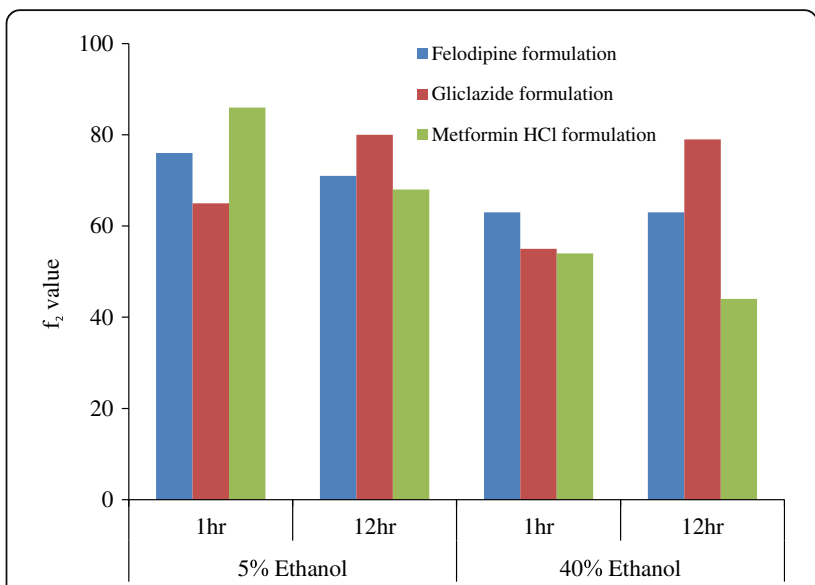

Fig. 20 Comparison of $f_{2}$ values for drug release profiles from HPMC matrices in ethanolic media to when they were not exposed to ethanol solutions (data from reference (Levina et al. 2007))

alcohol solubility was investigated by Colorcon (Levina et al. 2007, Table 5). Dissolution profiles over $12 \mathrm{~h}$ were performed at 0, 5 and $40 \%$ ethanol media at multiple time points ( 26 per profile). Two durations of alcohol exposure were performed for $1 \mathrm{~h}$ and for the entire $12 \mathrm{~h}$. The $1 \mathrm{~h}$ exposure was considered to be a more realistic model to exposures that would occur in vivo.

The 12-h alcohol exposure showed no significant change is drug release profiles for two of the three drugs. The metformin formulation did have a decrease in drug release profile at $40 \%$ ethanol medium that was caused by the decrease in solubility of metformin in alcohol.

The $1 \mathrm{~h}$ ethanol exposures followed by $11 \mathrm{~h}$ is the standard dissolution media did not show significant change in drug release profiles for all three drug at both 5 and $40 \%$ ethanol media (Figs. 18, 19, 20, 21, 22 and 23).

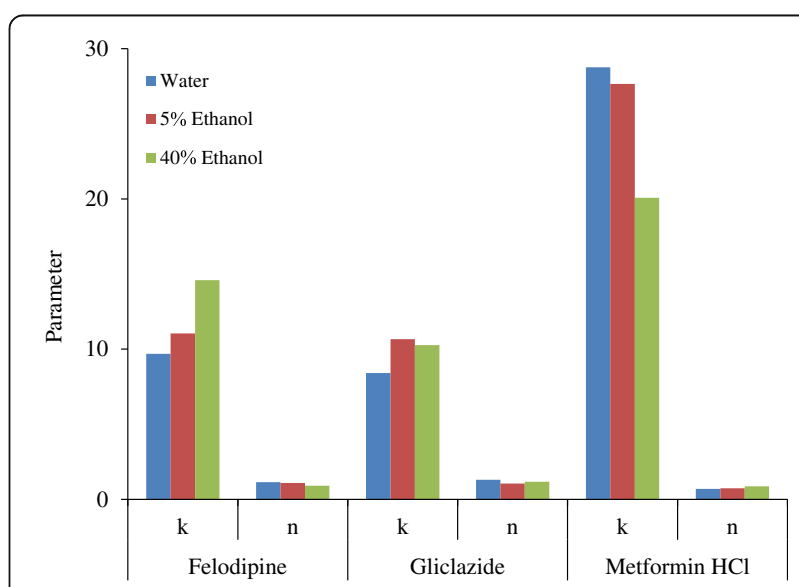

Fig. 21 Effect of alcohol on the kinetic constant $(k)$ and diffusional exponent $(n)$ for HPMC matrices $\left(R^{2}>0.99\right)$ (data from reference (Levina et al. 2007)) 


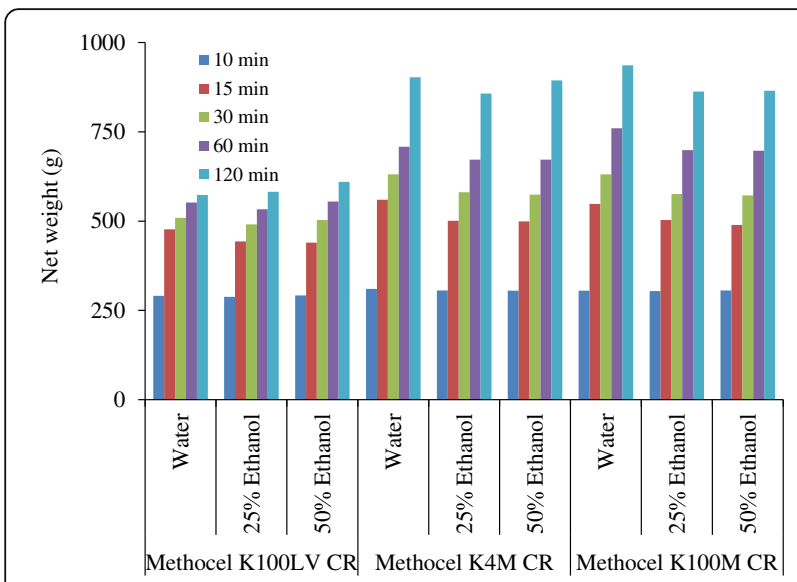

Fig. 22 Effect of hydroalcoholic media on wet weight of methocel compacts (data from reference (Levina et al. 2007))

\section{Effect of ethanol on aspirin in hypromellose matrices}

This paper looks the impact of various percentages of alcohol on dissolution and a variety of physicochemical properties of aspirin in a hypromellose (HPMC) matrix (Roberts et al. 2007). Dissolution profiles were performed on 0, 10, 20, 30 and 40\% ethanol in an acetate buffer media. Additional alcohol experiments included aspirin solubility, aspirin-HPMC compacting swelling, HPMC viscosity and cloud point.

Dissolution profiles through $6 \mathrm{~h}$ indicate that there is an increase in drug release with an increase in alcohol concentration, but the profiles do not show dose dumping. The experiments indicate that both an increase in aspirin solubility and reduction in matrix swelling at higher alcohol concentrations play

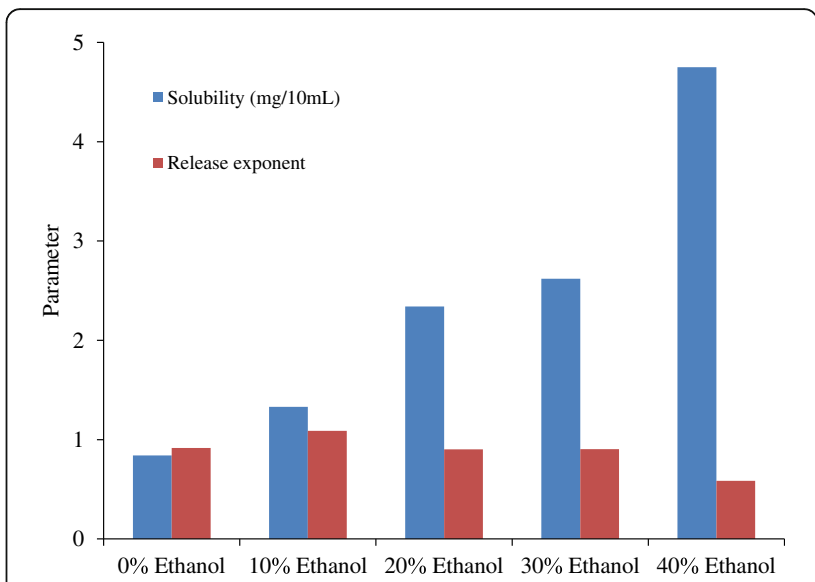

Fig. 24 Effect of ethanol on solubility of aspirin and its release exponent from hypromellose matrices (data from reference (Roberts et al. 2007))

competing roles in release of drug from the HPMC matrix in alcoholic media (Figs. 24 and 25).

\section{Effect of alcohol on drug release kinetics from hpmc-based matrix tablets using model drugs}

Six tablet formulations with HPMC were studied using diclofenac potassium, tramadol $\mathrm{HCl}$ and venlafaxine $\mathrm{HCl}$. The six formulations were tested with $\mathrm{pH} 6.8$ phosphate buffer using USP Apparatus 2 at $50 \mathrm{rpm}$ with media containing $0,10,20,30$, and $40 \%$ ethanol. In all cases, drug release increased with an increase in alcohol content in the dissolution medium. Drug release was faster for those formulations that had lactose as a filler as

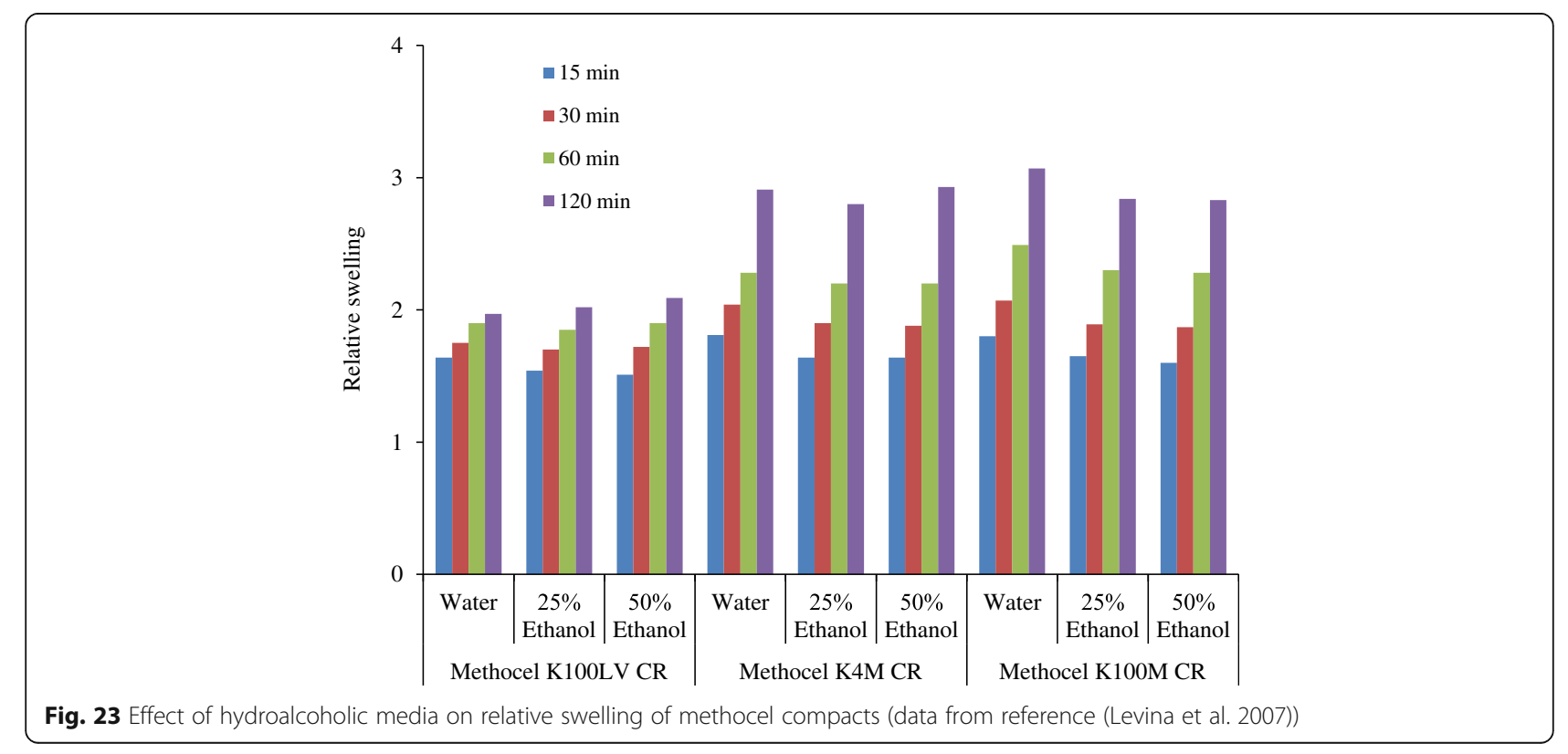




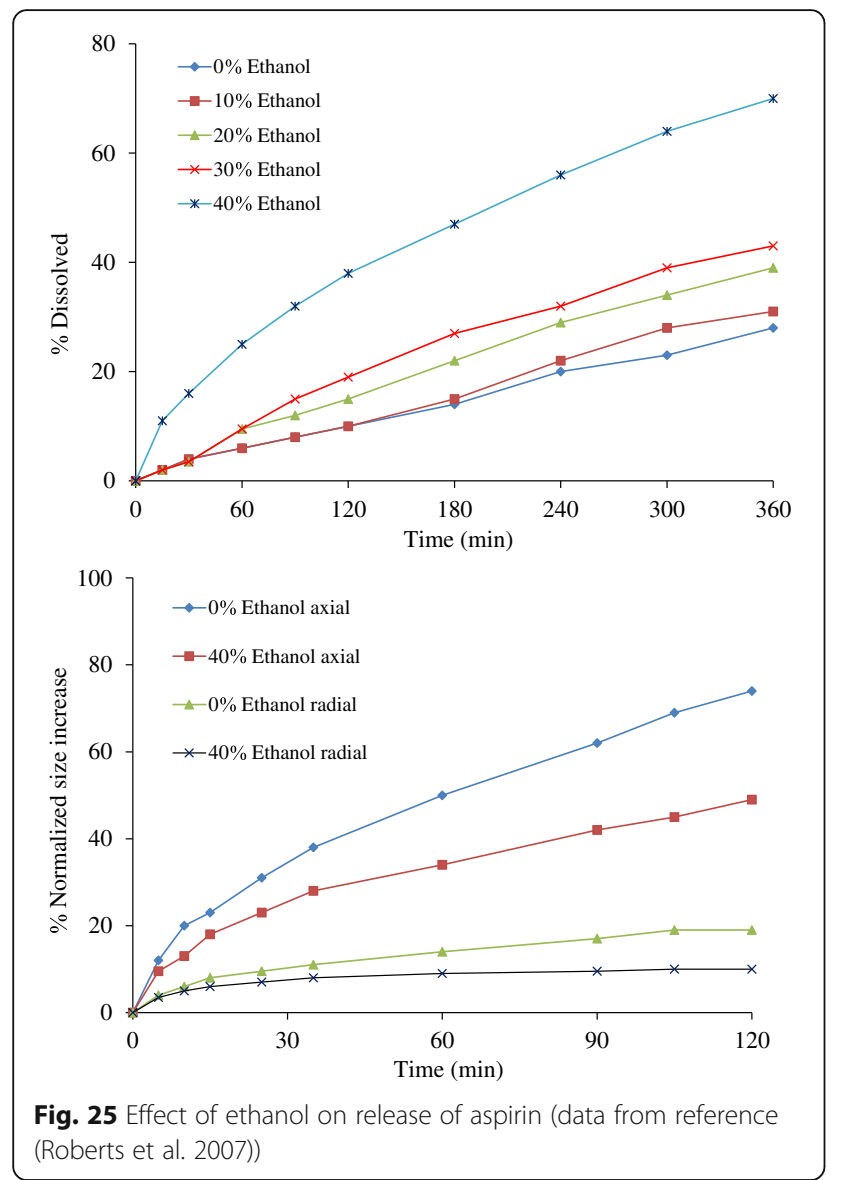

opposed to microcrystalline cellulose. All formulations failed $\mathrm{f}_{2}$ in the presence of dissolution medium containing $40 \%$ ethanol when compared to $0 \%$ ethanol medium (Table 6). Swelling studies demonstrate that swelling decreases with higher alcohol content in the dissolution medium (Figs. 26 and 27) (Avachat \& Nandare 2014).

\section{Ethanol effects on verapamil Meltrex}

Dissolution AIDD studies were performed on four commercially available extended release formulations of verapamil $240 \mathrm{mg}$ strength at 5, 10, 20 and $40 \%$ ethanol concentration (Roth et al. 2009). The dissolution for this

Table $6 f_{2}$ values for diclofenac (D), tramadol (T) and venlafaxine $(V)$ formulations in the presence of alcohol (data from reference (Avachat \& Nandare 2014))

\begin{tabular}{lllllll}
\hline \% Alcohol & \multicolumn{6}{l}{ Formulations } \\
\cline { 2 - 7 } in media & D1 & D2 & T1 & T2 & V1 & V2 \\
\hline $10 \%$ & 84 & 63 & - & - & - & - \\
$20 \%$ & 66 & 49 & 76 & 64 & 72 & 65 \\
$30 \%$ & 50 & 41 & - & - & - & - \\
$40 \%$ & 39 & 32 & 47 & 39 & 48 & 34 \\
\hline
\end{tabular}

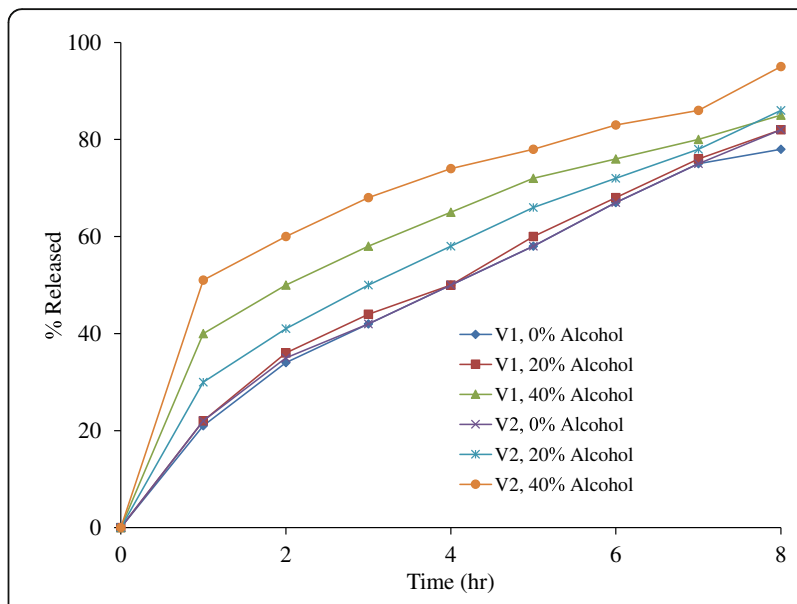

Fig. 26 Effect of alcohol on \% drug released from two venlafaxine tablets (V1 and V2) (data from reference (Avachat \& Nandare 2014))

product uses $900 \mathrm{~mL}$ of $\mathrm{pH} 6.8$ phosphate buffer dissolution media in USP Apparatus II and run for 8-10 h.

Results of the testing show similar release rates in the 4 alcohol media compared to the control without alcohol for verapamil Meltrex formulation. Verapamil Meltrex uses an innovative melt extrusion process to manufacture the tablets. The three other formulations have significantly accelerated release rates at the 20 and $40 \%$ alcohol levels. These results indicate that verapamil is not vulnerable to dose dumping in ethanol, whereas the other three formulations have significant AIDD at high alcohol concentrations (Fig. 28).

\section{Polyethylene oxide extended-release matrix tablets}

Two tablet formulations with polyethylene oxide (PEO) were studied using Gliciazide and metformin. The two tablet formulations were tested with 5 and $40 \%$ ethanol in water for $12 \mathrm{~h}$ and with exposure to the same alcohol

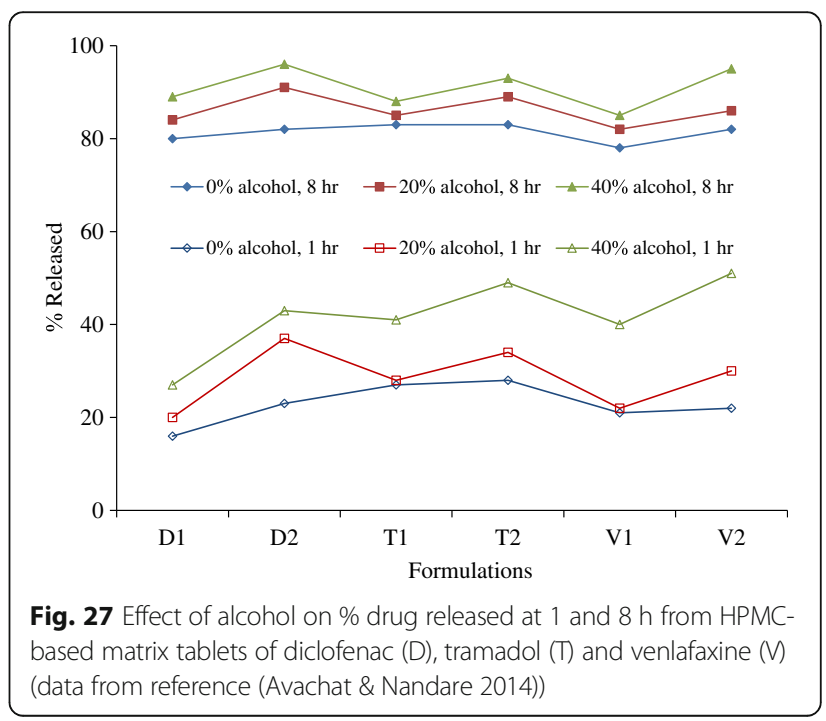




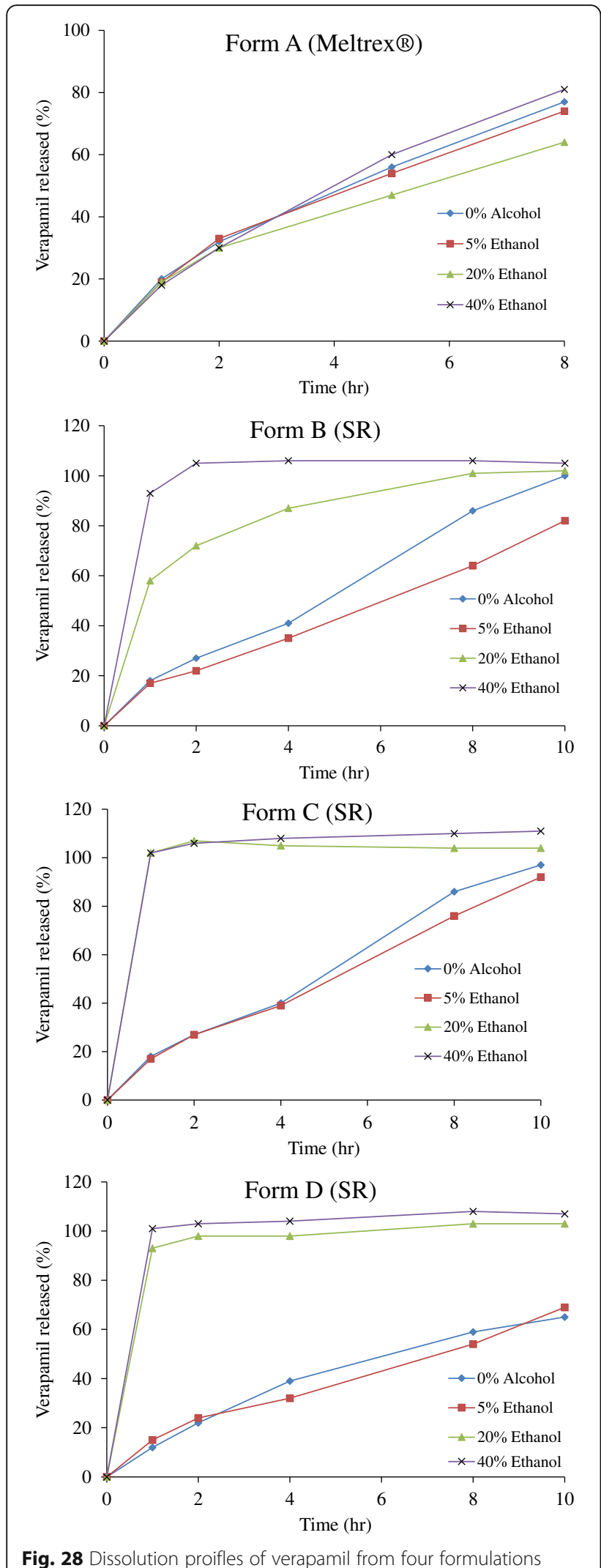

Fig. 28 Dissolution proifles of verapamil from four formulations
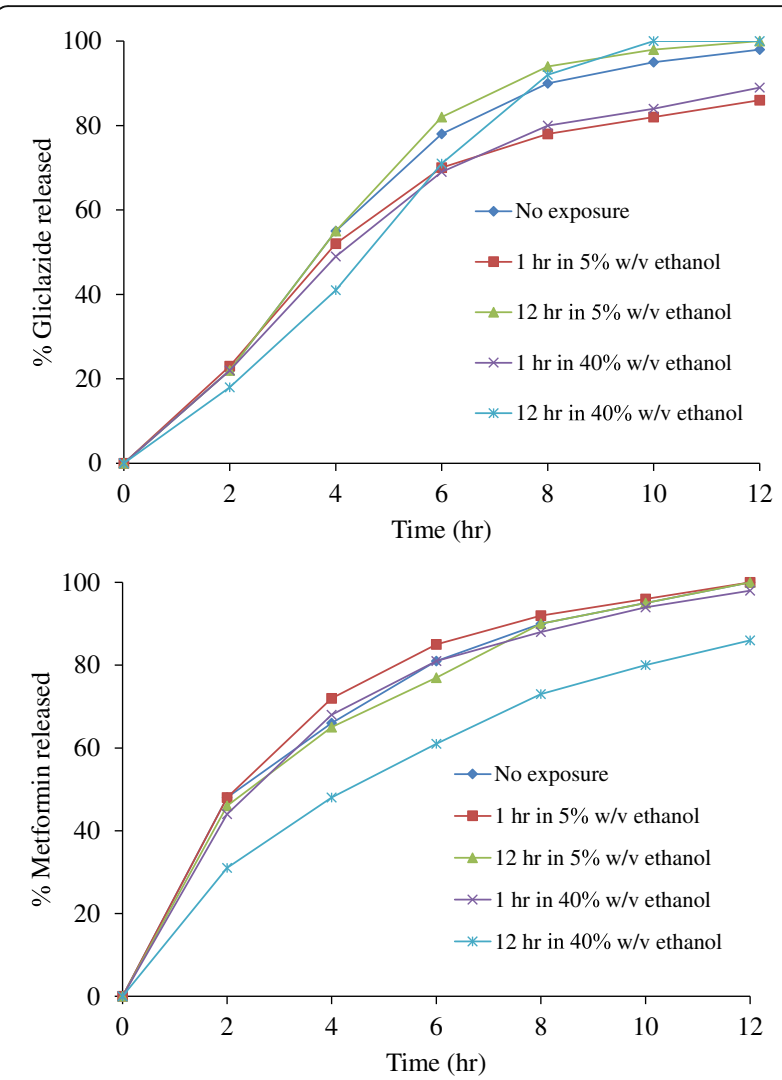

Fig. 29 Effect of alcohol on release of gliclazide and metformin from polyethylene oxide extended release matrices (data from reference (Palmer et al. 2011))

solutions for $1 \mathrm{~h}$ followed by dissolution with water (Fig. 29) (Palmer et al. 2011). The $f_{2}$ similarity results indicate that the dissolution profiles were not impacted by ethanol exposure in all conditions except the metformin in $40 \%$ ethanol for $12 \mathrm{~h}$. In this case, the release profile was

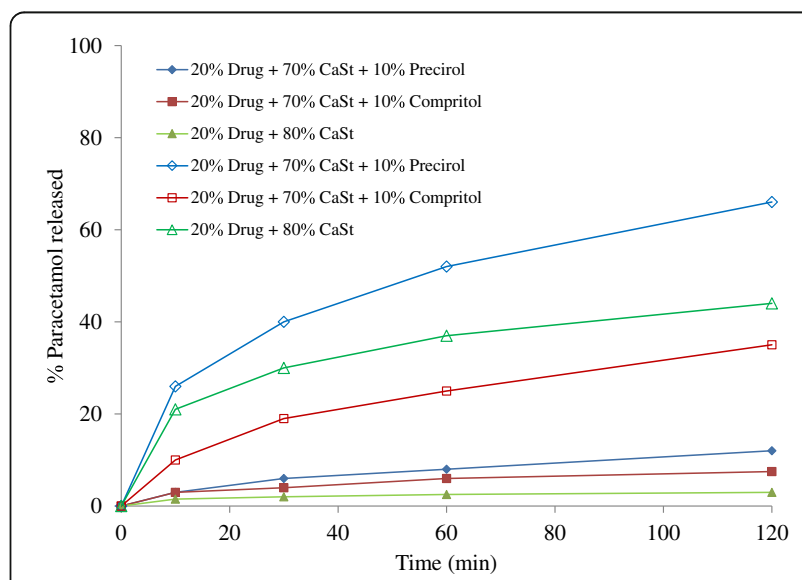

Fig. 30 Effect of ethanol concentration on release of paracetamol from hot melt extruded pellets (closed legends $=0 \%$ ethanol, open legends $=40 \%$ ethanol) (Jedinger et al. 2015) 


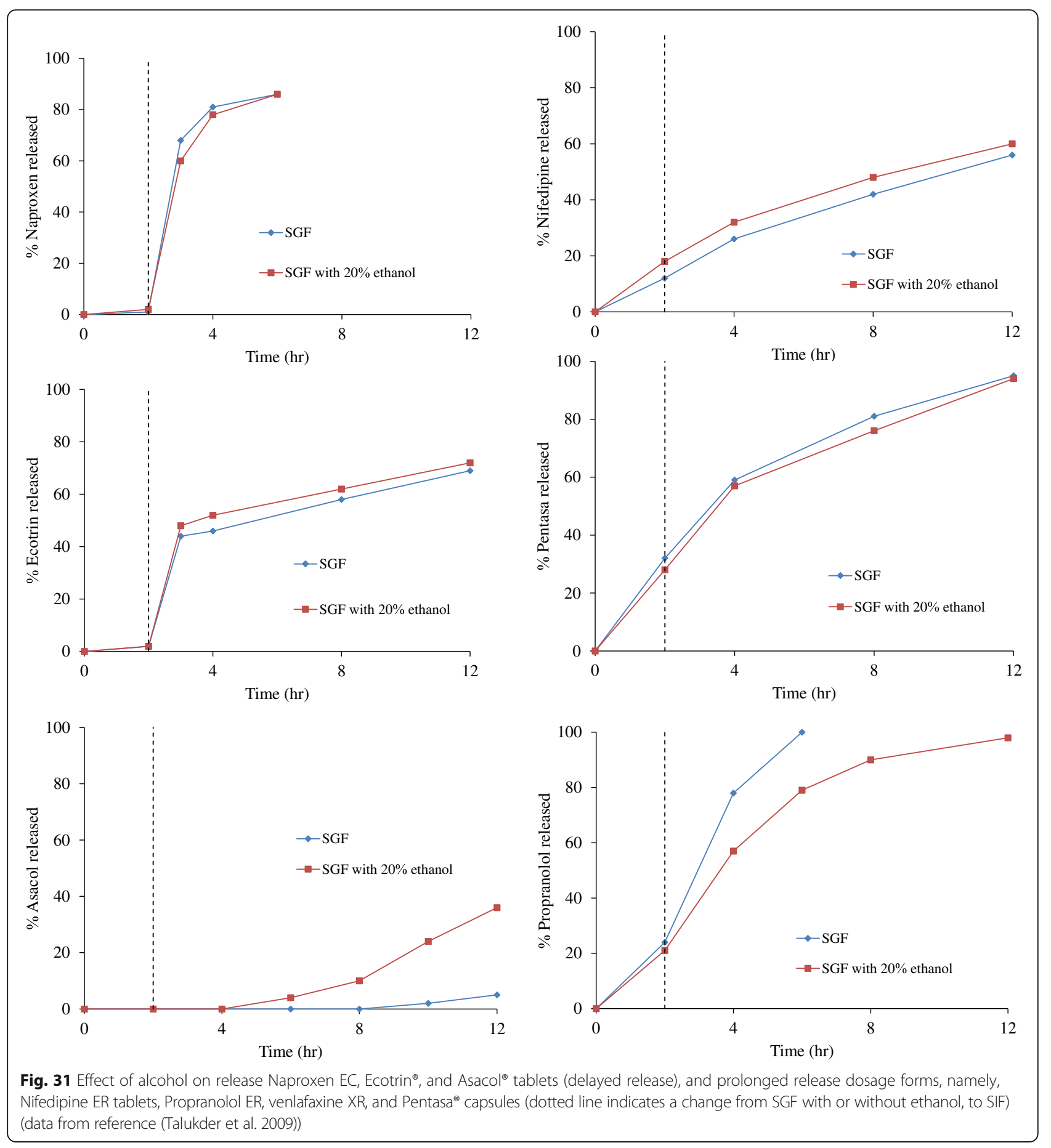

reduced indicating a resistance to alcohol dose dumping. Tablet swelling was slightly reduced in ethanol. These formulations were resistant to alcohol dose dumping.

\section{Paractemol hot melt extruded pellets}

In a manner similar to that described with codeine hot melt extruded pellets (Codeine hot melt extruded pellets section), the dissolution results of the paracetamol in $0 \%$ ethanol in
$0.1 \mathrm{~N} \mathrm{HCl}$ and $20 \%$ ethanol in $0.1 \mathrm{~N} \mathrm{HCl}$ were similar, so the 20\% data has not been presented (Fig. 30) (Jedinger et al. 2015). Paracetamol does not have significant release after $2 \mathrm{~h}$ in $0.1 \mathrm{~N} \mathrm{HCl}$ while in medium with $40 \%$ ethanol, dose dumping is observed. The formulation containing Precirol has the largest dose released after $2 \mathrm{~h}$. As in the study with codeine, the formulation containing Precirol has the largest dose released after $2 \mathrm{~h}$. 


\section{Evaluation of the effects of ethanol on dissolution of various types of modified release dosage forms}

Delayed release products, such as, Naproxen EC, Ecotrin ${ }^{\odot}$, and Asacol $^{\odot}$ tablets, and prolonged release dosage forms, namely, Nifedipine ER tablets, Propranolol ER, Venlafaxine XR, and Pentasa ${ }^{\circ}$ capsules were obtained from a local drug store. In-vitro evaluations of release characteristics of the dosage forms were conducted in $900 \mathrm{ml}$ of USP simulated gastric fluid without the enzymes (SGF) for $2 \mathrm{~h}$, followed by dissolution in simulated intestinal fluid without the enzymes (SIF) in a VanKel USP apparatus I at $50 \mathrm{rpm}$ using on-line UV spectrophotometric detection. To evaluate the effect of alcohol, the dissolutions were carried out in SGF with different levels of ethyl alcohol $(5,10$, and $20 \% \mathrm{v} / \mathrm{v})$ for $2 \mathrm{~h}$ followed by dissolution in SIF for $10 \mathrm{~h}$ (Fig. 31) (Talukder et al. 2009).

\section{Conclusions}

A comprehensive review has been presented of in vivo and in vitro studies that have investigated alcohol induced dose dumping (AIDD) in modified release dosage forms. The regulatory perspective of the FDA, EU and Canadian regulatory authorities has been reviewed. Some clinical case studies were discussed from some opioid extended-release PK studies. Lastly, a review of in vitro dissolution studies has been presented that demonstrate the impact of formulation excipients of modified release dose forms on release of drug with exposure to various levels of ethanol. The formulations in the case studies had a range of sensitivity to alcohol induced dose dumping. Based on information from regulatory authorities, those MR formulations that show significant AIDD may need to be reformulated. Alternately, less severe cases may require a clinical PK study to determine the extent of the impact of alcohol on the release of the drug.

\footnotetext{
Abbreviations

ACPS: Advisory Committee for Pharmaceutical Science; AIDD: Alcohol induced dose dumping; ANDA: Abbreviate new drug application; API: Active pharmaceutical ingredient; AUC: Area under the curve; CDER: Center for Drug Evaluation and Research; CNS: Central nervous system; CR: Controlled-release; DAWN: Drug Abuse Warning Network; DBE: Division of Bioequivalence; DSC: Differential scanning calorimetry; EMA: European Medicines Agency; ER: Extended release; EU: European Union; FDA: Food and Drug Administration; FT-IR: Fourier transform infrared; Gl: Gastro intestinal; $\mathrm{HCl}$ : Hydrochloric acid; HCTZ: Hydrochlorothiazide; HPMC: Hydroxy propyl methyl cellulose; IR: Immediate release; MR: Modified-release; MS-sNT: Morphine sulfate with sequestered naltrexone; OROS: Osmotic release oral system; PEO: Polyethylene oxide; PK: Pharmacokinetics; SGF: Simulated gastric fluid; SIF: Simulated intestinal fluid; TPD: Therapeutic Products Directorate; USP: United States Pharmacopeia
}

\section{Acknowledgments}

This review paper was performed and authored under the auspices of the In vitro Release and Dissolution Testing (IVRDT) Focus Group, of the American Association of Pharmaceutical Scientists (AAPS). Susan (chair-elect), Stephen and Alger (past chairs) are members of the IVRDT Focus Group. Susan D'Souza is currently affiliated with Tesaro, an oncology focused biopharmaceutical company. Stephen Mayock is Director of Analytical Development and Quality Control at Collegium Pharmaceutical, Inc., a company that develops abuse deterrent extended release, opioid drug products. Alger Salt is affiliated with H\&A Scientific, Inc., a scientific and laboratory software company.

\section{Authors' contributions}

This review article was a collaborative effort by the three authors, Susan D'Souza (SD), Alger Salt (AS) and Stephen Mayock (SM). The three authors were involved in the design and scope of the article. AS, SD and SM performed the literature search with SM providing some articles from his library. The search articles were evenly divided among the three authors to read and determine whether they were appropriate for the article. Each author was assigned different sections to write. SD drafted the introduction and conclusion. Sections in the body of the article were drafted by AS, SD and SM. Drafts of the sections were shared among the group for editing and comments. Figures and tables prepared by AS, SD and SM, were submitted to SD for formatting consistency. All authors read and approved the final manuscript.

\section{Competing interests}

The authors declare that they have no competing interests.

\section{Publisher's Note}

Springer Nature remains neutral with regard to jurisdictional claims in published maps and institutional affiliations.

\section{Author details}

${ }^{1}$ Tesaro Inc., 1000 Winter Street, Suite \#3300, Waltham, MA 02451, USA. ${ }^{2}$ Collegium Pharmaceutical Inc., 780 Dedham St., Suite \#800, Canton, MA 02021, USA. ${ }^{3}$ H\&A Scientific, Inc., 105A Regency Blvd., Greenville, NC 27834, USA.

Received: 20 July 2016 Accepted: 14 April 2017

Published online: 07 June 2017

\section{References}

(1999) Note for guidance on quality of modified release products: a oral dosage forms, B: transdermal dosage forms section 1 (Quality), in, European Medicines Agency Committee for Proprietary Medicinal Products. http:// www.ema.europa.eu/docs/en_GB/document_library/Scientific_guideline/ 2009/09/WC500003664.pdf

(2010) European Medicines Agency concludes review of modified-release oral opioids of the WHO level III scale for the management of pain (Press Release)

(2011) Effect of Alcohol on the Drug Dissolution Properties of Tablets Formulated with Carbopol ${ }^{\circledast *}$ Polymers, Lubrizol Technical Data Sheet 793.

(2014) Guideline on the pharmacokinetic and clinical evaluation of modified release dosage forms (EMA/CPMP/EWP/280/96 Corr1). in, Committee for Medicinal Products for Human Use (CHMP). http://www. ema.europa.eu/docs/en_GB/document_library/Scientific_guideline/2014/ 11/WC500177884.pdf

(2012) The DAWN Report: highlights of the 2010 Drug Abuse Warning Network (DAWN) findings on drug-related emergency department visits, in: (SAMSHA) Center for Behavioral Health Statistics and Quality, Rockville, MD. https:// www.samhsa.gov/data/sites/default/files/DAWN096/DAWN096/ SR096EDHighlights2010.pdf

Anand O, Yu LX, Conner DP, Davit BM (2011) Dissolution testing for generic drugs: An FDA perspective. AAPS J 13:328-225

Avachat AM, Nandare DS (2014) Effect of alcohol on drug release kinetics from HPMC-based matrix tablets using model drugs. Dissolut Technol 21:11-17

Avinza Package Insert, Ligand Pharmaceuticals Inc, San Diego, CA

Barkin RL, Shirazi D, Kinzler E (2009) Effect of ethanol on the release of morphine sulfate from Oramorph SR tablets. Am J Ther 16:482-486

Bernstein KT, Bucciarelli A, Piper TM, Gross C, Tardiff K, Galea S (2007) Cocaineand opiate-related fatal overdose in New York City, 1990-2000. BioMedCentral Public Health 7:31

CDER/FDA (2002) Guidance for Industry, Food-Effect Bioavailability and Fed Bioequivalence Studies

CDER/FDA (2014) Bioavailability and Bioequivalence Studies Submitted in NDAs or INDs - General Considerations (Draft Guidance) 
de Kater A, Butera P, Haux E, Schoenhard G, Friedmann N (2008) The Effects of Alcohol on an Abuse-resistant Formulation of Controlled release Oxycodone. Poster presented at International Association for the Study of Pain, Glasgow

EMA, Quality of medicines questions and answers: Part 2, Subchapter: Specific types of product-Need for in-vitro dissolution studies with alcohol for modified release oral products including opioid drug products, in, http:// www.ema.europa.eu/ema/index.jsp?curl=pages/regulation/q_and_a/q_and_ a_detail_000072.jsp\#section 10

Emeje MO, Nwabunike PI, Isimi CY, Kunle OO, Ofoefule SI (2008) Hydro-alcoholic media: an emerging in vitro tool for predicting dose dumping from controlled release matrices. J Pharmacol Toxicol 3:84-92

Fadda HM, Mohamed MAM, Basit AW (2008) Impairment of the in vitro drug release behaviour of oral modified release preparations in the presence of alcohol. Int J Pharm 360:171-176

Farr SJ, Robinson CY, Rubino CM (2015) Effects of food and alcohol on the pharmacokinetics of an oral, extended-release formulation of hydrocodone in healthy volunteers. Clin Pharmacol 7:1-9

FDA (2005) Information for healthcare professionals: hydromorphone hydrochloride extended-release capsules (marketed as Palladone), https://www.fda.gov/Drugs/ DrugSafety/PostmarketDrugSafetylnformationforPatientsandProviders/ ucm129288.htm. Accessed 25 Sept 2013.

FDA (2005b) Summary Minutes of the Pharmaceutical Science Advisory Committee

Franke A, Teyssen S, Harder H, Singer MV (2004) Effect of ethanol and some alcoholic beverages on gastric emptying in humans. Scand J Gastroenterolgy 39:638-644

Hendeles L, Wubbena P, Weinberger M (1984) Food-induced dose dumping of once-a-day theophylline. Lancet (London, England) 2:1471

Hendeles L, Weinberger M, Milavetz G, Hill M, Vaughan L (1985) Food-induced "dose-dumping" from a once-a-day theophylline product as cause of theophylline toxicity. Chest 87:758-765

Higaki K, Choe SY, Löbenberg R, Welage LS, Amidon GL (2008) Mechanistic understanding of time-dependent oral absorption based on gastric motor activity in humans. Eur J Pharm Biopharm 70:313-325

Jedinger N, Schrank S, Mohr S, Feichtinger A, Khinast J, Roblegg E (2015) Alcohol dose dumping: The influence of ethanol on hot-melt extruded pellets comprising solid lipids. Eur J Pharm Biopharmaceutics.

Johnson F, Ciric S, Boudriau S (2007) An evaluation of the effect of ethanol on the pharmacokinetics of extended release morphine (Kadian ${ }^{\circledR}$ ). Clin Pharm Ther 81:S75

Johnson F, Wagner G, Sun S, Stauffer J (2008) Effect of concomitant ingestion of alcohol on the in vivo pharmacokinetics of KADIAN (morphine sulfate extended-release) capsules. J Pain 9:330-336

Johnson FK, Ciric S, Boudriau S, Kisicki J, Stauffer J (2012) Effects of alcohol on the pharmacokinetics of morphine sulfate and naltrexone hydrochloride extended release capsules. J Clin Pharmacol 52:747-756

Karim A, Burns T, Janky D, Hurwitz A (1985a) Food-induced changes in theophylline absorption from controlled-release formulations. Part II. Importance of meal composition and dosing time relative to meal intake in assessing changes in absorption. Clin Pharmacol Ther 38:642-647

Karim A, Burns T, Wearley L, Streicher J, Palmer M (1985b) Food-induced changes in theophylline absorption from controlled-release formulations. Part I. Substantial increased and decreased absorption with Uniphyl tablets and Theo-Dur Sprinkle. Clin Pharmacol Ther 38:77-83

Levina M, Vuong H, Rajabi-Siahboomi AR (2007) The influence of hydro-alcoholic media on hypromellose matrix systems. Drug Dev Ind Pharm 33:1125-1134

Linnoila M, Mattila MJ, Kitchell BS (1979) Drug interactions with alcohol. Drugs 18: 299-311

Makin A, Williams R (2000) Paracetamol hepatotoxicity and alcohol consumption in deliberate and accidental overdose. Q J Med 93:341-349

Messiha FS, Barnes CD (1979) Cyclobenzaprine and ethanol interaction. Pharmacol Biochem Behav 10:947-949

Opana ER Package Insert, Endo Pharmaceuticals Inc., Chadds Ford, PA

Palmer D, Levina M, Farrell TP, Rajabi-Siahboomi AR (2011) The influence of hydro-alcoholic media on drug release from polyethylene oxide extendedrelease matrix tablets. Pharm Technol 35:50-58

Palva ES, Linnoila M, Saario I, Mattila MJ (1979) Acute and subacute effects of diazepam on psychomotor skills: interaction with alcohol. Acta Pharmacol Toxicol 45:257-264

Roberts M, Cespi M, Ford JL, Dyas AM, Downing J, Martini LG, Crowley PJ (2007) Influence of ethanol on aspirin release from hypromellose matrices. Int J Pharm 332:31-37
Rosiaux Y, Muschert S, Chokshi R, Leclercq B, Siepmann F, Siepmann J (2013) Ethanol-resistant polymeric film coatings for controlled drug delivery. J Control Release 169:1-9

Roth W, Setnik B, Zietsch M, Burst A, Breitenbach J, Sellers E, Brennan D (2009) Ethanol effects on drug release from Verapamil Meltrex ${ }^{\oplus}$, an innovative melt extruded formulation. Int J Pharm 368:72-75

Sathyan G, Sivakumar K, Thippawong J (2008) Pharmacokinetic profile of a 24hour controlled-release OROS formulation of hydromorphone in the presence of alcohol. Curr Med Res Opin 24:297-305

Schiller C, Fröhlich CP, Giessmann T, Siegmund W, Mönnikes H, Hosten N, Weitschies W (2005) Intestinal fluid volumes and transit of dosage forms as assessed by magnetic resonance imaging. Aliment Pharmacol Ther 22:971-979

Serdula MK, Brewer RD, Gillespie C, Denny CH, Mokdad A (2004) Trends in alcohol use and binge drinking, 1985-1999: results of a multi-state survey. Am J Prev Med 26:294-298

Smith AP, Moore TW, Westenberger BJ, Doub WH (2010) In vitro dissolution of oral modified-release tablets and capsules in ethanolic media. Int J Pharm 398:93-96

Steffensen G, Pedersen S (1986) Food induced changes in theophylline absorption from a once-a-day theophylline product. Br J Clin Pharmacol 22:571-577

Talukder RM, Pilkington M, Fassihi R, Missaghi S (2009) Evaluation of the Effects of Ethanol on Dissolution of Various Types of Modified Release Dosage Forms, Abstract AAPS

Traynor MJ, Brown MB, Pannala A, Beck P, Martin GP (2008) Influence of alcohol on the release of tramadol from 24-h controlled-release formulations during in vitro dissolution experiments. Drug Dev Ind Pharm 34:885-889

Walden M, Nicholls FA, Smith KJ, Tucker GT (2007) The effect of ethanol on the release of opioids from oral prolonged-release preparations. Drug Dev Ind Pharm 33:1101-1111

Weathermon R, Crabb DW (1999) Alcohol and medication interactions. Alcohol Res Health 23:40-54

\section{Submit your manuscript to a SpringerOpen ${ }^{\circ}$ journal and benefit from:}

- Convenient online submission

- Rigorous peer review

- Immediate publication on acceptance

- Open access: articles freely available online

- High visibility within the field

- Retaining the copyright to your article

Submit your next manuscript at $>$ springeropen.com 